\title{
Oxytocin and socioemotional aging: Current knowledge and future trends
}

\author{
Natalie C. Ebner ${ }^{1 *}$, Gabriela M. Maura ${ }^{1}$, Kai MacDonald ${ }^{2}$, Lars Westberg ${ }^{3}$ and Håkan Fischer ${ }^{4,5}$ \\ 1 Department of Psychology, University of Florida, Gainesville, FL, USA \\ ${ }^{2}$ Department of Psychiatry, University of California, San Diego, La Jolla, CA, USA \\ ${ }^{3}$ Department of Pharmacology, University of Gothenburg, Gothenburg, Sweden \\ ${ }^{4}$ Department of Psychology, Stockholm University, Stockholm, Sweden \\ ${ }^{5}$ Aging Research Center, Karolinska Institute, Stockholm, Sweden
}

Edited by:

Susanne Leiberg, University of

Zurich, Switzerland

\section{Reviewed by:}

Gregory R. Samanez-Larkin, Yale University, USA

Brian W. Haas, University of

Georgia, USA

\section{*Correspondence:}

Natalie C. Ebner, Department of

Psychology, University of Florida,

Psychology Building, 945 Center

Drive, PO Box 112250, Gainesville,

FL 32611, USA

e-mail: natalie.ebner@ufl.edu
The oxytocin (OT) system is involved in various aspects of social cognition and prosocial behavior. Specifically, OT has been examined in the context of social memory, emotion recognition, cooperation, trust, empathy, and bonding, and-though evidence is somewhat mixed-intranasal OT appears to benefit aspects of socioemotional functioning. However, most of the extant data on aging and OT is from animal research and human OT research has focused largely on young adults. As such, though we know that various socioemotional capacities change with age, we know little about whether age-related changes in the OT system may underlie age-related differences in socioemotional functioning. In this review, we take a genetic-neuro-behavioral approach and evaluate current evidence on age-related changes in the OT system as well as the putative effects of these alterations on age-related socioemotional functioning. Looking forward, we identify informational gaps and propose an Age-Related Genetic, Neurobiological, Sociobehavioral Model of Oxytocin (AGeNeS-OT model) which may structure and inform investigations into aging-related genetic, neural, and sociocognitive processes related to OT. As an exemplar of the use of the model, we report exploratory data suggesting differences in socioemotional processing associated with genetic variation in the oxytocin receptor gene (OXTR) in samples of young and older adults. Information gained from this arena has translational potential in depression, social stress, and anxiety-all of which have high relevance in aging - and may contribute to reducing social isolation and improving well-being of individuals across the lifespan.

Keywords: oxytocin, aging, socioemotional functioning, amygdala, anterior cingulate
Social and emotional processes and their associated genetic and neurobiological mechanisms in aging are still incompletely understood (Nielsen and Mather, 2011). In this paper we propose to combine neuroendocrine, genetic, and sociobehavioral approaches to examine the role of the oxytocin (OT) system in the context of socioemotional aging. Aspects of the OT system warranting investigation include: (1) changes in endogenous and dynamic OT levels; (2) changes in systems which directly impact OT function (i.e., gonadal hormones); (3) genetic variation in aspects of the OT system, including the gene for oxytocin $(O X T)$, its receptor (OXTR), and the related CD38 system; (4) changes in OT-rich neural regions; (5) the effect of exogenous OT. There is increasing evidence that OT plays a significant role in many of the socioemotional capacities that undergo age-related changes. However, to date, very little is known about the role of OT in human aging (Huffmeijer et al., 2012). Thus, it will be crucial for future research to clarify links between age-related changes in the aforementioned aspects of the OT system and changes in neural processing and subsequent alterations in experience as well as behavior in socioemotional domains in older compared to young adults.

To foreshadow, this focused review conceptually integrates two lines of research. First, we summarize evidence for age-associated changes in socioemotional capacities (Isaacowitz et al., 2007; Ruffman et al., 2008; Scheibe and Carstensen, 2010). Second, we review evidence for the involvement of OT in socioemotional functioning (Bartz et al., 2011; Meyer-Lindenberg et al., 2011; Van IJzendoorn and Bakermans-Kranenburg, 2012). Synthesizing these two lines of work, we present an Age-Related Genetic, Neurobiological, Sociobehavioral Model of Oxytocin (AGeNeS-OT model) which may stimulate questions and organize investigations into the role of OT in socioemotional aging. As an example of the use of the AGeNeS-OT model, we report preliminary data suggesting neural and behavioral differences in socioemotional processing associated with genetic variations in OXTR in samples of young and older adults. We conclude by suggesting future directions for research implied by the model. Ultimately, these investigations will increase our understanding of the role of OT in aging and will have the 
potential for generating new interventions to improve health and well-being.

\section{SOCIOEMOTIONAL FUNCTIONING AND AGING}

From life's beginning, humans are confronted with critical, survival-enhancing socioemotional stimuli related to self and others. To maintain successful social interactions and avoid the negative consequences of social isolation (Baumeister and Leary, 1995; Norman et al., 2011), we learn to quickly and accurately process, respond to, and remember social cues (BaronCohen et al., 2000; Grady and Keightley, 2002; Adolphs, 2003). Socioemotional functioning may become particularly relevant in old age when-due to the experience of increasing physical ailment, dependency, and age-related social losses-the experience of social isolation often increases with negative effects on physical and mental health (Cornwell and Waite, 2009).

The extant literature suggests a mixed picture of age-related changes in socioemotional capabilities: Some capacities (e.g., emotion regulation, emotional problem solving) improve with age, whereas other skills (e.g., recognition of emotions in others) decline (cf. Scheibe and Carstensen, 2010). In particular, across various studies, older compared to young adults show increased emotion regulation capacity (Carstensen, 2006; Blanchard-Fields et al., 2007; Riediger et al., 2009; Scheibe and Blanchard-Fields, 2009; Voelkle et al., 2013) and greater confidence in this ability (Lawton et al., 1992; Gross and Levenson, 1997; Kessler and Staudinger, 2009). The majority of older adults are well-adjusted emotionally and report relatively high levels of affective wellbeing and emotional stability as documented in cross-sectional (Carstensen et al., 2000) as well as longitudinal (Carstensen et al., 2011) studies (see also Charles et al., 2001; Teachman, 2006). In addition, older compared to young adults are at least equally (and often more) effective in their ability to regulate their emotional experiences, autonomic arousal, and outward display of negative emotions in language and faces when instructed to do so (Kunzmann et al., 2005; Magai et al., 2006; Phillips et al., 2008), and show improved socioemotional problem solving capacity (Blanchard-Fields et al., 2007).
At the same time, older adults often show increased difficulties in accurate recognition of social and emotional cues (for reviews see Isaacowitz et al., 2007; Ruffman et al., 2008; see also Ebner and Johnson, 2010; see Figure 1A). Recent functional magnetic resonance imaging (fMRI) data suggests that these difficulties are associated with greater activity in dorsomedial prefrontal cortex (dmPFC) in older compared to young adults during facial emotion reading, particularly for angry expressions (Williams et al., 2006; Keightley et al., 2007; Ebner et al., 2012; see Figure 1C). This association comports with previous evidence that dmPFC is involved in complex processing and cognitive and emotional control (Amodio and Frith, 2006). Another age-related change in socioemotional functioning is that older compared to young adults demonstrate more interpersonal trust (List, 2004; Castle et al., 2012). This change may be due to the difficulty older adults often have in "reading" the emotions of others, as suggested by recent findings that older compared to young adults are less proficient at detecting lies, mediated by deficits in emotion recognition (Ruffman et al., 2012). With respect to changes in memory, there is evidence that the majority of older adults experience declines in remembering critical socioemotional cues, including names (Crook et al., 1993; Verhaeghen and Salthouse, 1997) and faces (Bartlett et al., 1989; Grady et al., 1995; Ebner and Johnson, 2009; see Figure 1B). Finally, in terms of social motivation, there is robust evidence that older adults are more avoidance-oriented and less approach-oriented than young adults (Ebner et al., 2006; Freund, 2006; Nikitin et al. in revision).

Importantly, the mechanisms underlying these age-related changes in socioemotional functioning are not well-understood yet. One potential explanation is differences in visual processing (Isaacowitz et al., 2006; Ebner et al., 2011), perhaps as a function of age-related changes in motivation (Mather and Carstensen, 2005; Carstensen, 2006; Samanez-Larkin and Carstensen, 2011). In particular, there is evidence that older compared to young adults spend more time looking at positive than negative information (Isaacowitz et al., 2006) and, when processing faces, spend less time viewing the eye region and more time viewing the mouth
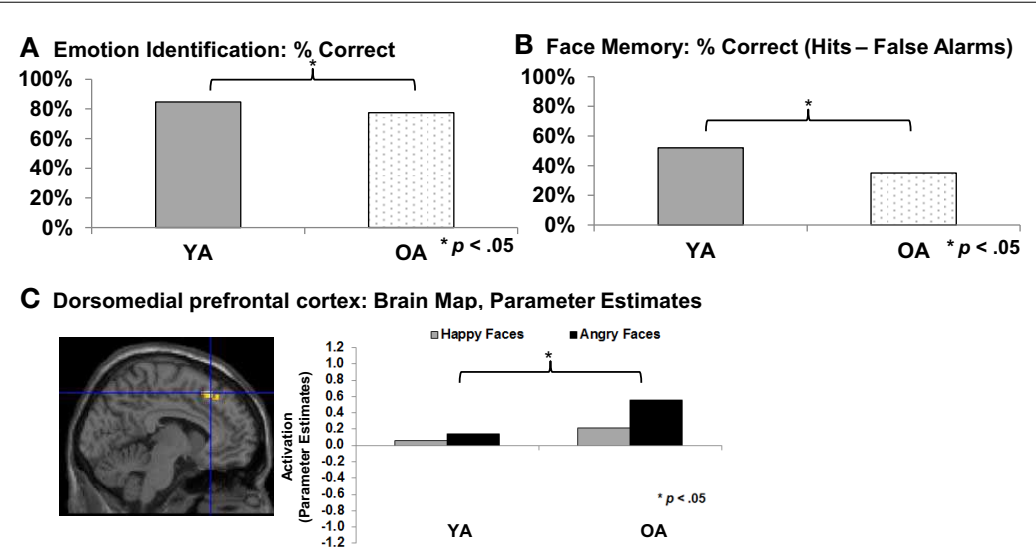

FIGURE 1 | (A) Emotion identification (Ebner et al., 2010); (B) Face memory (Ebner and Johnson, 2009); (C) Emotion identification: dorsomedial prefrontal cortex (Ebner et al., 2012). YA, Young adults; OA, Older adults. 
(Firestone et al., 2007). This age-differential visual processing pattern may be important given that the eye vs. mouth regions of a face carry different socioemotional information (Calder et al., 2000; Ebner et al., 2011).

A complementary, mechanistic explanation for age-related changes in socioemotional function may be changes in brain structure or function in regions associated with socioemotional processing such as amygdala, PFC, insula, or fusiform gyrus (Keightley et al., 2007; Grady, 2008; Cacioppo et al., 2009; Ebner et al., 2012; see Ruffman et al., 2008; Samanez-Larkin and Carstensen, 2011; St. Jaques et al., 2013, for overviews). For instance, there is well-documented, age-related structural decline in regions such as the lateral PFC (IPFC), insula, and striatum (Raz, 2005; Raz et al., 2005). Regarding functional changes, one common finding is an age-related decrease in amygdala activation during the perception of emotional stimuli (especially negative stimuli) accompanied by an age-related increase in activity in a number of IPFC and mPFC regions (Iidaka et al., 2002; GunningDixon et al., 2003; Fischer et al., 2005, 2010; Tessitore et al., 2005; but see Mather and Carstensen, 2005; Wright et al., 2006; Ebner et al., 2013).

Crucially, however, extant literature suggests that age-related differences in socioemotional processing cannot be explained solely by age-related visuoperceptual and/or neurocognitive changes (Samanez-Larkin and Carstensen, 2011). In addition, it may be that changes in socioemotional function are also linked with age-related alterations in neuroendocrine function. In particular, the neuropeptide OT appears as a particularly promising candidate, given increasing evidence of its role in socioemotional domains (Insel and Fernald, 2004; Donaldson and Young, 2008; Bartz et al., 2011; Meyer-Lindenberg et al., 2011; Norman et al., 2011). However, to date, we know very little about age-related changes in the OT system, particularly in the context of socioemotional aging (Huffmeijer et al., 2012).

\section{OXYTOCIN AND SOCIOEMOTIONAL FUNCTIONING}

OT is a nine amino acid peptide, with peripheral and central functions (Gimpl and Fahrenholz, 2001). It is synthesized in magnocellular neurosecretory cells of paraventricular nuclei (PVN) and supraoptic nuclei (SON) of the hypothalamus and released through the posterior pituitary gland into the periphery (Insel, 2010). OT is also released into the brain by magnocellular dendrites (Leng and Ludwig, 2006) and by OT-releasing neurons projecting to specific brain regions such as the amygdala, hippocampus, and striatum (Kimura et al., 1992; Landgraf and Neumann, 2004; Knobloch et al., 2012). Human and animal studies combined suggest that the function of the OT system is reflected at a variety of physiological and anatomical levels, including: (1) peripheral hormone levels (i.e., plasma and saliva); (2) central hormone levels [i.e., in cerebrospinal fluid (CSF)]; (3) histological levels (i.e., presence and size of OT cells); (4) receptor levels (in OT receptor binding in defined brain regions); (5) genetic levels, or the level of "neuropeptidergic individuality" (MacDonald, 2012); i.e., polymorphisms related to OXT or OXTR, or genes related to OT release (i.e., CD38; Sauer et al., 2012, 2013).
In particular, accumulating evidence suggests that OT may serve as a key effector in socioemotional functioning such as emotion recognition, memory for faces, interpersonal trust, and bonding as briefly summarized next (see Bartz et al., 2011; Meyer-Lindenberg et al., 2011; Norman et al., 2011; Zink and Meyer-Lindenberg, 2012, for comprehensive overviews).

After the discovery that certain neuropeptides could be delivered intranasally to the human brain (Born et al., 2002), a number of experimental studies using intranasal OT revealed intriguing effects on diverse aspects of socioemotional functioning. For example, research in healthy adults suggests that OT impairs performance in verbal memory tasks (Ferrier et al., 1980; Heinrichs et al., 2004; but see Feifel et al., 2012), while enhancing recognition of social (i.e., faces) but not non-social stimuli (Rimmele et al., 2009; see also Heinrichs et al., 2004), especially for neutral and angry compared to happy faces (Savaskan et al., 2008). Furthermore, intranasal administration of OT increases overall gaze time toward faces (Guastella et al., 2008; Andari et al., 2010; Averbeck, 2010; Gamer et al., 2010) and increases emotion recognition, specifically of happy and fearful faces (and under certain conditions angry faces; see Shahrestani et al., 2013, for a recent review).

In addition, recent studies have shown that intranasal OT increases facial trustworthiness and attractiveness ratings (Theodoridou et al., 2009) as well as interpersonal trust and the willingness to take social risks (Kosfeld et al., 2005; Baumgartner et al., 2008; Phan et al., 2010). These effects of OT on trust seem to be particularly pronounced in positive social interactions (Zak et al., 2005; Mikolajczak et al., 2010) and with respect to ingroup vs. out-group members (Van IJzendoorn and BakermansKranenburg, 2012). Moreover, these effects seem moderated by interindividual differences (Rockliff et al., 2011; but see Guastella et al., 2013), including genetic polymorphisms associated with OT function (Riedl and Javor, 2011; see also Rodrigues et al., 2009; MacDonald, 2012, for reviews).

Besides these effects on facial processing and trust, intranasal OT has been shown to influence social approach behavior, attachment, bonding, and social rejection with associated health benefits (Ditzen et al., 2009; Gouin et al., 2010; Scheele et al., 2012; Schneiderman et al., 2012; Fekete et al., 2013). For example, intranasal OT increased positive relative to negative behaviors during a laboratory couple conflict and reduced post-conflict cortisol levels (Ditzen et al., 2009). This potential stress reducingeffect of OT has been further documented by evidence that participants with increased plasma OT healed faster and had a greater number of positive interactions with partners during a 24-h hospital stay (Gouin et al., 2010; see also Kéri and Kiss, 2011; Kiss et al., 2011; see Taylor et al., 2006, for a discussion of OT's role during relaxation vs. stress; see also Feldman et al., 2011).

An ever-expanding body of neuroimaging data suggests that OT's effects on socioemotional functioning are due to its attenuation of the neural circuitry for anxiety and aversion and its activation of social reward neural networks (cf. Yoshida et al., 2009; Zink and Meyer-Lindenberg, 2012). In particular, a number of studies have provided evidence that the amygdala might be a key structure for the mediation of the social-cognitive effects of OT (Kirsch et al., 2005; Domes et al., 2007a; Petrovic et al., 
2008; Singer et al., 2008; Labuschagne et al., 2010; Riem et al., 2011; Zink and Meyer-Lindenberg, 2012; cf. Huffmeijer et al., 2012; but see Domes et al., 2010). For example, OT attenuates amygdala response to fear-inducing stimuli (Kirsch et al., 2005). Baumgartner et al. (2008; see also Kosfeld et al., 2005; Mikolajczak et al., 2010) provide evidence that OT reduced betrayal aversion to breaches of trust via a reduction in bilateral amygdala activation and midbrain regions and greater ventral striatum and orbitofrontal cortex (OFC) activity. Furthermore, there are suggestions of specific modulatory influences of OT on subregions within the amygdala during processing of socioemotional information (Gamer et al., 2010; see also Huber et al., 2005; Viviani et al., 2011; Knobloch et al., 2012). These central effects, importantly, occur in interaction with a network of other neurochemicals including estrogen, dopamine, and serotonin (Riedl and Javor, 2011).

Thus there are suggestions in the literature that OT increases approach-related behaviors, while decreasing withdrawal-related behaviors (Kemp and Guastella, 2010). At the same time, however, there is evidence suggesting that OT may play a somewhat more complex role in social behavior than simply directing approach vs. avoidance behavior and/or attentional biases to positive and negative information, respectively. Rather, OT may increase social engagement, salience of social agents, and social value of processed information, largely independent of valence (Shamay-Tsoory et al., 2009; Tops, 2009; Shamay-Tsoory, 2010; Bartz et al., 2011). In line with this suggestion, brain regions such as the ventral tegmentum, PFC, nucleus accumbens, and insula associated with the social-reward neural network have shown sensitive to OT (Balleine et al., 2007; Riem et al., 2011; WittfothSchardt et al., 2012; Groppe et al., 2013; Scheele et al., 2013).

The central effects of OT are mediated by its G-proteincoupled receptor, located on a variety of tissues including the brain, heart, kidney, and uterus (Loup et al., 1991; Gimpl and Fahrenholz, 2001). Polymorphisms of the gene encoding the OT receptor, OXTR, have been shown to contribute to individual differences in various social phenotypes (cf. Gimpl and Fahrenholz, 2001; Meyer-Lindenberg et al., 2011; Ebstein et al., 2012; Zink and Meyer-Lindenberg, 2012; Kumsta et al., 2013; Westberg and Walum, 2013). For example, OXTR single nucleotide polymorphisms (SNPs) have been associated with lower positive affect (Lucht et al., 2009), lower levels of responsiveness of mothers to their toddlers (Bakermans-Kranenburg and van IJzendoorn, 2008), lower empathy scores and increased stress reactivity (Rodrigues et al., 2009), non-verbal displays of prosociality (Kogan et al., 2011), and pair-bonding (Walum et al., 2012). OXTR SNPs have also been studied in relation with autism spectrum disorder (ASD; see Ebstein et al., 2012, for a review), with evidence that they contribute to risk for some phenotypes observed in ASD (Egawa et al., 2012; but see Tansey et al., 2010).

Taken together, this review highlights the importance of simultaneously considering behavioral, neural, and genetic perspectives when examining OT's role in socioemotional functioning, as will be discussed in more detail below (see Figure 2). In addition, it raises five important caveats and informational gaps.

First, some of the effects associated with OT are inconsistent and come from small, homogeneous samples, creating a

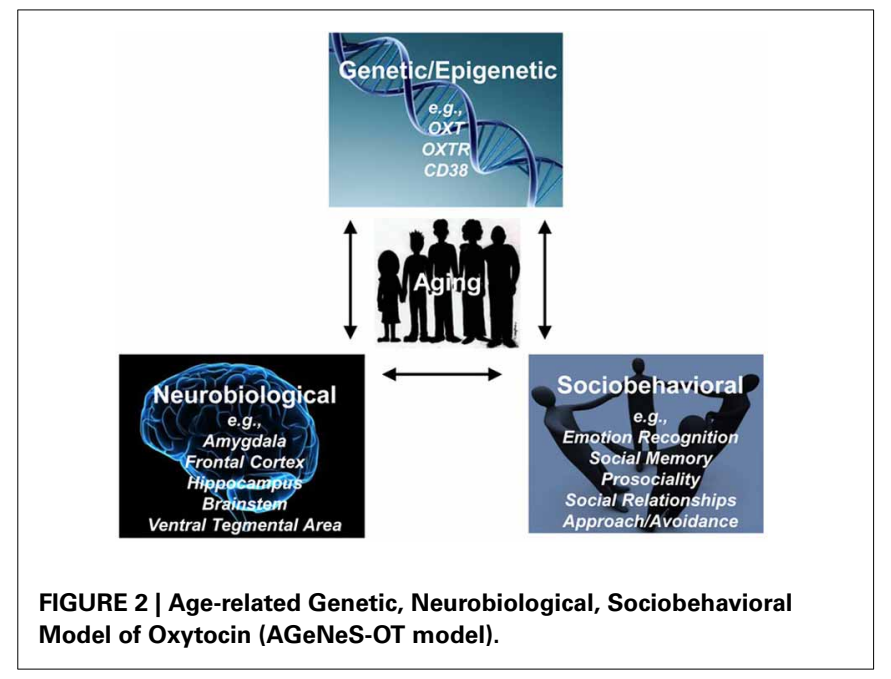

need for replication of key findings in larger, more representative samples.

Second, many of OT's effects seem to vary by individual difference variables such as the level of social proficiency (Bartz et al., 2011; but Guastella et al., 2013).

Third, there is increasing evidence suggesting that the effects of OT are dependent on context (Domes et al., 2007b) and influenced by early life experiences (see MacDonald, 2012, for a review). For example, women (Heim et al., 2008) and men (Meinlschmidt and Heim, 2007) who were abused or neglected as children showed altered OT system sensitivity as adults (e.g., decreased CSF level of OT; see also Winslow et al., 2003; Fries et al., 2005; but see Anderson, 2006; cf. MacDonald, 2012, for a review).

Fourth, due to both theoretical safety concerns using OT in women as well as the complexity introduced by OT's sex-specific effects, a large majority of studies conducted so far refer to men exclusively, even though there are growing indications that some of OT's effects may differ by sex (Savaskan et al., 2008; Guastella et al., 2009; Domes et al., 2010; Marsh et al., 2010; cf. MacDonald, 2012). This sex-specific pattern raises the possibility that the effects of OT on social cognition may be differentially regulated by gonadal steroids (estrogen and testosterone) or other sex-specific biological factors (Choleris et al., 2009; Gabor et al., 2012; see also Van Anders et al., 2011; see also Weisman and Feldman, 2013).

A fifth shortcoming in the current human literature on oxytocin-critical in the present context-is that current studies have almost exclusively been conducted with young adults. Given the aforementioned evidence of age-group differences in socioemotional functioning (Scheibe and Carstensen, 2010; SamanezLarkin and Carstensen, 2011), a comprehensive examination of aging-related aspects of the OT system (including genetic, neurobiological, and behavioral aspects) is warranted (Huffmeijer et al., 2012).

\section{OXYTOCIN AND AGING}

Despite a significant need for research addressing the growing older segment of the population, research on OT and aging is scarce and inconclusive. To date, the few studies that have 
addressed age-related differences in the OT system almost exclusively refer to non-human species with limited applicability to humans (Quinn, 2005). Also, studies conducted to date are characterized by large methodological differences in terms of species examined, OT parameters measured, brain regions targeted, etc., which makes a direct comparison difficult and a meta-analytic approach not feasible. Most importantly, a theoretical framework for generating hypotheses regarding age-related differences in the OT system (including changes in endogenous OT physiology, function, and differential response to exogenous OT) is entirely lacking (cf. Huffmeijer et al., 2012).

Table 1 provides a summary of the current studies on OT and aging. Whereas some studies suggest no noticeable effects of aging on the OT system (Fliers et al., 1985; Zbuzek et al., 1988; Wierda et al., 1991; Arletti et al., 1995), other studies report agerelated change (Fliers and Swaab, 1983; Melis et al., 1992, 1995; Arsenijevic et al., 1995; Parker et al., 2010). Notably, some of the studies reporting comparability of the OT system across older and

Table 1 | Literature Review on Oxytocin and Aging.

\begin{tabular}{|c|c|c|c|c|c|}
\hline Authors & Species & Age group & Measurement & Difference & Main findings \\
\hline \multicolumn{6}{|c|}{ EVIDENCE OF STABILITY IN THE OT SYSTEM IN AGING } \\
\hline Arletti et al. (1995) & Rats (M) & $\mathrm{O}$ & $\begin{array}{l}\text { Intraperitoneal OT } \\
\text { injection }\end{array}$ & $O=Y$ & $\begin{array}{l}\text { Comparable improved social memory } \\
\text { and anti-depressant effect of OT } \\
\text { injection }\end{array}$ \\
\hline Fliers et al. (1985) & Rats (M) & $\mathrm{Y} / \mathrm{O}$ & OT fiber density & $O=Y$ & $\begin{array}{l}\text { Comparable OT fiber density in the } \\
\text { brain }\end{array}$ \\
\hline Wierda et al. (1991) & Human $(\mathrm{M}, \mathrm{F})$ & $\mathrm{Y} / \mathrm{O}$ & $\begin{array}{l}\text { Number of OT } \\
\text { cells in PVN } \\
\text { (post-mortem) }\end{array}$ & $O=Y$ & $\begin{array}{l}\text { Comparable numbers of } \\
\text { OT-expressing cells in PVN (normal } \\
\text { aging and Alzheimer's Disease) }\end{array}$ \\
\hline Yu et al. (2006) & Rats (M) & $\mathrm{Y} / \mathrm{O}$ & $\begin{array}{l}\text { OT cell size and } \\
\text { numbers in SON }\end{array}$ & $O=Y$ & $\begin{array}{l}\text { Comparable cell numbers, cell size, or } \\
\text { reactive density of NOS-expressing } \\
\text { neurons }\end{array}$ \\
\hline \multicolumn{6}{|c|}{ EVIDENCE OF CHANGE IN THE OT SYSTEM WITH AGE } \\
\hline Arsenijevic et al. (1995) & Rats (M) & $\mathrm{Y} / \mathrm{O}$ & $\begin{array}{l}\text { OT receptor } \\
\text { binding }\end{array}$ & $\mathrm{O}<\mathrm{Y}$ & $\begin{array}{l}\text { Age-related decrease in binding to OT } \\
\text { receptors in caudate putamen, } \\
\text { olfactory tubercle, and ventromedial } \\
\text { hypothalamic nucleus }\end{array}$ \\
\hline Fliers and Swaab (1983) & Rats (M) & Y/MA/O & Plasma OT levels & $\begin{array}{l}\mathrm{O}>\mathrm{Y} \\
\text { (neurosecretory } \\
\text { activity) } \\
\mathrm{O}=\mathrm{Y} \text { (plasma } \\
\text { levels) }\end{array}$ & $\begin{array}{l}\text { Age-related increase in OT secretion } \\
\text { in PVN (but not SON); Comparable } \\
\text { plasma OT levels }\end{array}$ \\
\hline Keck et al. (2000) & Rats (M) & $\mathrm{O}$ & $\begin{array}{l}\text { Intracerebral and } \\
\text { peripheral OT } \\
\text { release patterns }\end{array}$ & $\begin{array}{l}\mathrm{O}>\mathrm{Y} \\
\text { (peripheral) } \\
\mathrm{O}<\mathrm{Y} \\
\text { (intracerebral) }\end{array}$ & $\begin{array}{l}\text { Age-related increase in basal } \\
\text { peripheral OT secretion and decrease } \\
\text { in stress-induced intra-PVN OT } \\
\text { secretion }\end{array}$ \\
\hline Melis et al. (1992) & Rats (M) & Y/MA/O & OT levels & $\begin{array}{l}\mathrm{O}<\mathrm{Y}(\mathrm{CNS}) \\
\mathrm{O}=\mathrm{Y}(\mathrm{HNS} \text { and } \\
\text { plasma })\end{array}$ & $\begin{array}{l}\text { Age-related decrease in OT levels in } \\
\text { septum and hippocampus; } \\
\text { comparable OT levels in } \\
\text { hypothalamus and hypophysis, and no } \\
\text { change for plasma OT levels }\end{array}$ \\
\hline Melis et al. (1995) & Rats (M) & Y/MA/O & $\begin{array}{l}\text { OT-like } \\
\text { immunoreactive } \\
\text { peptides in thymic } \\
\text { extract }\end{array}$ & $O>Y$ & $\begin{array}{l}\text { Age-related increase in content of } \\
\text { OT-like immunoreactive peptides in } \\
\text { thymic extract }\end{array}$ \\
\hline Parker et al. (2010) & Rhesus monkeys (F) & Y/O & CSF OT levels & $\mathrm{O}>\mathrm{Y}$ & $\begin{array}{l}\text { CSF OT levels positively correlated } \\
\text { with adult female age (but negatively } \\
\text { correlated with infant age) }\end{array}$ \\
\hline Zbuzek et al. (1988) & Rats (M) & $\mathrm{O}$ & $\begin{array}{l}\text { Plasma and } \\
\text { hypothalamic OT } \\
\text { concentration }\end{array}$ & $\begin{array}{l}\mathrm{O}=\mathrm{Y} \text { (plasma, } \\
\text { hypothalamic } \\
\text { concentration) } \\
\mathrm{O}>\mathrm{Y} \text { (secretory } \\
\text { release) }\end{array}$ & $\begin{array}{l}\text { Comparable OT concentration in } \\
\text { plasma and hypothalamus; age-related } \\
\text { increase in secretory release of OT }\end{array}$ \\
\hline
\end{tabular}

Y, Young subjects; MA, Middle-aged subjects; O, Older subjects; M, Male; F, Female; OT, Oxytocin; PVN, Paraventricular nuclei of hypothalamus; SON, Supraoptic nuclei (SON) of hypothalamus; AVP, Arginine vasopressin; NOS, Nitric oxide synthase; CSF, Cerebrospinal fluid. 
young subjects refer to peripheral OT levels (Fliers and Swaab, 1983; Zbuzek et al., 1988; Melis et al., 1992), whereas several of the studies documenting age-related change relate to central OT levels (Fliers and Swaab, 1983; Melis et al., 1992; Arsenijevic et al., 1995; Parker et al., 2010). Thus, it is possible that aging may change OT transmission in the CNS but not in the neurohypophyseal (peripheral) system (Melis et al., 1999). A summary of the evidence reported in Table 1 would be that current evidence does not allow yet a firm conclusion of the existence or direction of age-related changes in the OT system, leaving the question open to empirical examination.

To our knowledge, only one very recent study explicitly examined the effects of intranasal OT in a group of older men (mean age of 80 years) focusing on OT's effects on social engagement and physical health (Barraza et al., 2013). Results from this double-blind, placebo-controlled 10-day clinical trial suggested improvement in dispositional gratitude in older adults in the OT compared to the placebo group. In addition, the OT group had a slower decline in physical functioning and decreased self-reported fatigue than the placebo group. No changes in mood, cardiovascular states, or social activity and engagement patterns were observed across the study interval. Importantly, this study did not include a comparison group of young adults and did not extensively explore OT's effects on other aspects of socioemotional functioning. Thus, it is critical to follow up on these first promising findings regarding OT and aging and to conduct systematic examinations of age differences in baseline levels of OT. In addition, a comprehensive evaluation of both single-dose as well as longer-term administration of intranasal OT and its effect on socioemotional functioning in young and older men and women is warranted. Finally, these studies should take into account genetic variations related to OT.

\section{OXYTOCIN AND SOCIOEMOTIONAL AGING: AGE-RELATED GENETIC, NEUROBIOLOGICAL, SOCIOBEHAVIORAL MODEL OF OXYTOCIN}

Based on the following rationale, we propose an OT X Age interaction (see Figure 3C) as the guiding working hypothesis for future research on the role of OT in socioemotional aging: As mentioned above, there is early evidence that the beneficial effects of OT in socioemotional domains (see Figure 3A) vary by individual factors (Bartz et al., 2011). Notably, "preexisting social impairment" seems to play a role, in that more socially impaired individuals benefit more from OT than less socially impaired individuals (Bartz et al., 2010; Guastella et al., 2010; but see Bakermans-Kranenburg and van IJzendoorn, 2013). Also there may be a "ceiling effect," a point beyond which OT cannot further improve social abilities (Bartz et al., 2011). As laid out above, older adults experience deficits in various socioemotional capacities (Scheibe and Carstensen, 2010; see Figure 3B), rendering them more socially impaired than young adults in some regards. Therefore, it may well be that OT is particularly beneficial in older compared to young adults (see Figure 3C).

However, an alternative hypothesis exists: As reported above, even though some aspects of socioemotional functioning (i.e., emotion recognition and memory for emotional information) decline with age, other aspects increase or remain stable. That is,

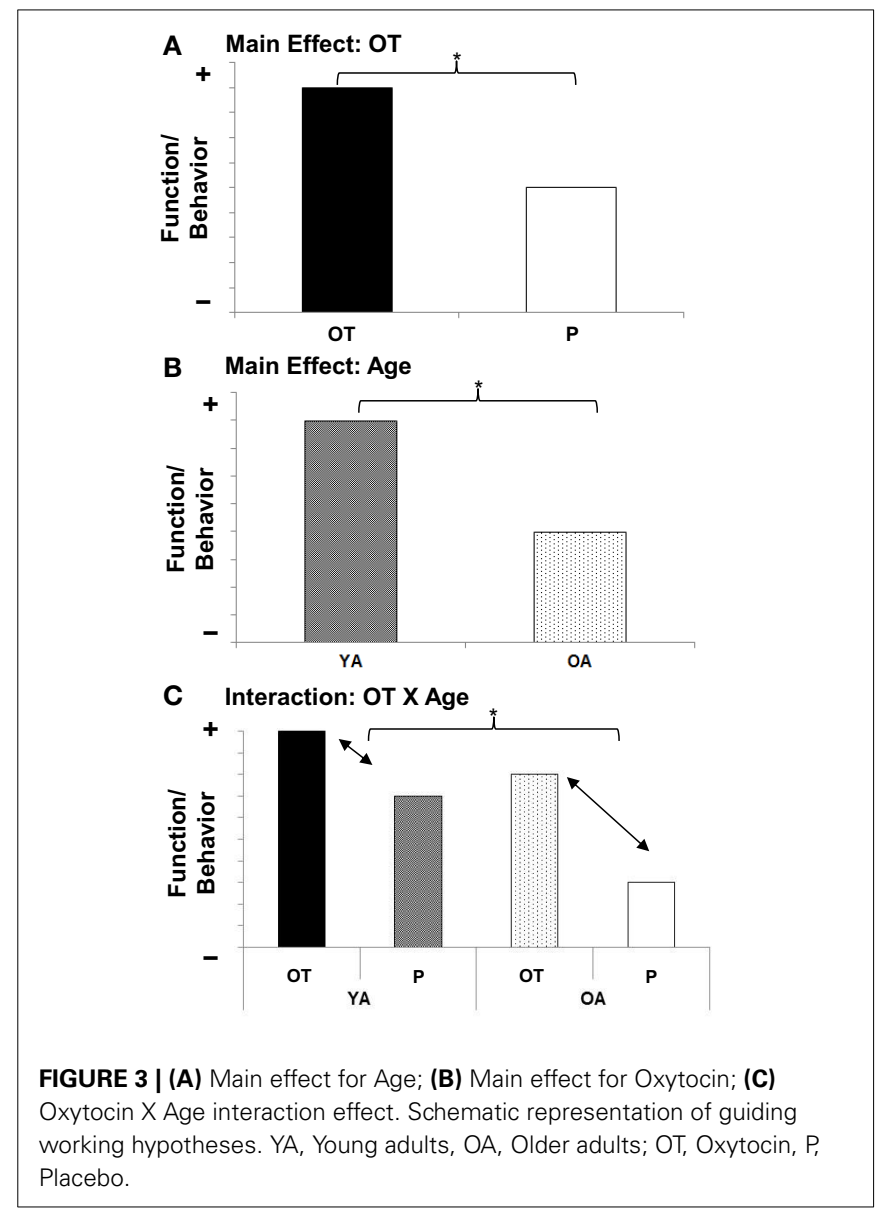

given broad evidence for a positivity effect and for healthy socioemotional functioning in old age (Carstensen, 2006; Carstensen et al., 2011), as well as some evidence for increased trustworthiness in old age (Castle et al., 2012), on average, older adults can be described as highly positive, trustworthy, and prosocial. These characteristics may be adaptive in some contexts (e.g., social interactions within close relationships) but maladaptive in others (e.g., putting aging adults at greater susceptibility to fraud). This reasoning, combined with the current lack of proof that aging is associated with declines in the OT system and mixed evidence regarding OT's effect on cognitive performance (Heinrichs et al., 2004; Feifel et al., 2012), suggest the possibility that under certain circumstances OT may have harmful effects in older adults. Given that OT is currently being investigated in clinical populations such as schizophrenia (cf. MacDonald and Feifel, 2012, 2013), comprising samples of people who are late middle-aged, a thorough investigation of age-related aspects of the OT systemincluding beneficial or detrimental effects on outcome measures in socioemotional as well as cognitive domains-will be crucial.

As summarized above, the OT system is represented at genetic, neural, and behavioral levels (Meyer-Lindenberg et al., 2011). Furthermore, each of these levels and their functional interactions are influenced by the aging process. We therefore propose for future research in the domain of OT and socioemotional aging to adopt an Age-Related Genetic, Neurobiological, Sociobehavioral Model of Oxytocin (AGeNeS-OT model; Figure 2). In particular, 
this model suggests that a comprehensive examination of the central OT system should consider interactions between OT-related genes (OXT, OXTR, CD38; Meyer-Lindenberg et al., 2011; Sauer et al., 2013), the brain (e.g., amygdala, frontal cortex, brainstem, ventral tegmental area; Pedersen et al., 1994; Kirsch et al., 2005; Balleine et al., 2007; Baumgartner et al., 2008; Gamer et al., 2010), and behavior (e.g., social memory, emotion identification, approach/avoidance biases; Rimmele et al., 2009; Domes et al., 2010; Lischke et al., 2011), by combining genetics, functional and structural brain imaging, and sociobehavioral measures. Crucially, the model proposes that interactions between neuroendocrine and sociobehavioral factors need to be considered from a developmental perspective, taking age variations into account. Along these lines, the model offers a theoretical framework to address vital research questions: (1) Are OT-related genotypes associated with composition and quality of social networks in the elderly? How do brain structures involved in social processing such as mPFC and OFC, temporoparietal junction, or amygdala mediate these relationships? (2) Is older adults' increased social avoidance compared to approach motivation represented in neural processing differences in brain networks involving PFC and amygdala? To what extent do these associations interact with OT-related genotypes? (3) Are detrimental effects that early abuse has on morbidity and mortality in the elderly moderated by OT-related genotypes or OT levels? How is this relationship structurally and functionally represented in the brain? (4) Are effects of social relationships on cognitive functioning in the elderly mediated by the OT system (either OT-levels or OT-related genotypes)? Do structural changes in brain regions such as the hippocampus underlie this relationship?

In the attempt to provide a concrete empirical application of the AGeNeS-OT Model, we here present a preliminary report of an experiment in which we examined associations between $O X T R$ polymorphisms, brain activity and behavioral response during reading of facial emotions in young and older adults. This exploratory, secondary data analysis was based on our group's previous finding of increased activation in ventromedial PFC (vmPFC) during emotion identification of happy compared to angry faces and increased dorsomedial PFC (dmPFC) activity to angry compared to happy faces (Ebner et al., 2012; see also Keightley et al., 2007) in both young and older adults. In the present set of analyses, we examined the extent to which these processing differences in $\mathrm{mPFC}$ would be further qualified when considering OXTR polymorphisms in both of the age groups. In particular, we examined (1) the extent to which OXTR polymorphisms were associated with differences in young and older adults' brain activity in bilateral mPFC (Haxby et al., 2000, 2002; Pessoa and Adolphs, 2010; Ebner et al., 2012) during a facial emotion reading task; and (2) the extent to which OXTR polymorphisms were associated with young and older adults' ability to read facial emotions.

Young $[n=25,12$ females, $M=25.1$ years $(S D=3.6$, range $=20-31)]$ and older $[n=29,17$ females, $M=68.3$ years $(S D=2.8$, range $=65-74)]$ healthy participants underwent fMRI on a $3 \mathrm{~T}$ Siemens Magnetom TrioTim scanner, while identifying happy, neutral, and angry facial emotions (see Ebner et al.,
2012, for details on participants, study design, and image acquisition). Participants were subsequently genotyped by KBioscience (http://www.kbioscience.co.uk) using KASPar methodology for 14 OXTR single nucleotide polymorphisms (SNPs in order from the $3^{\prime}$ to the $5^{\prime}$ end: rs7632287, rs6770632, rs1042778, rs237887, rs2268493, rs2254298, rs53576, rs237897, rs4686302, rs4564970, rs2301261, rs2268498, rs2270465, rs75775), previously shown to be associated with social behavior (Apicella et al., 2010; MeyerLindenberg et al., 2011; Ebstein et al., 2012; Walum et al., 2012; Westberg and Walum, 2013).

Data from this event-related fMRI study was analyzed using Statistical Parametric Mapping (SPM5; Wellcome Department of Imaging Neuroscience) and pre-processing and data analysis was conducted as reported in Ebner et al. (2012). The following $T$-contrasts were specified across young and older adults, based on our previous findings (Ebner et al., 2012): (1) Happy Faces $>$ Angry Faces, (2) Angry Faces > Happy Faces. We focused on select regions of interest (ROIs: bilateral medial frontal gyrus and anterior cingulate gyrus) in which we had previously seen processing differences for happy vs. angry faces, at a threshold of $p<0.05$, FDR corrected. For each region of activation identified by these two contrasts, peak voxel beta values were extracted for each participant to produce a single value for each condition of interest. These values are depicted in the bar graphs of Figure 4 . In the fashion of follow-up $F$ - and $t$-tests $(p<0.05)$, for each of the 14 OXTR SNPs that were genotyped, we examined differences in brain activation between polymorphisms across the total sample as well as separately for young and older adults. The most consistent associations found in these analyses were in relation to OXTR rs237887 (cf. Lerer et al., 2008; Israel et al., 2009; Liu et al., 2010; Lori et al., 2012; but see Apicella et al., 2010).

OXTR rs237887 AA carriers $(n=10$ young participants; $n=10$ older participants) and GA/GG carriers ( $n=15$ young participants; $n=19$ older participants) were comparable in terms of chronological age, level of education, cognitive status (e.g., Mini Mental State Examination; Folstein et al., 1975; 2-Back Digits Task; Kirchner, 1958; Verbal Fluency Task; Lezak, 1995), and affective variables (Geriatric Depression Scale; Brink et al., 1982; Gottfries, 1997; State-Trait Anxiety Inventory; Spielberger et al., 1970).

For the contrast Happy Faces > Angry Faces, we found greater BOLD response to happy compared to angry faces in bilateral anterior cingulate cortex (ACC; MNI: $x=3, y=45, z=0$ and $x=-3, y=51, z=0$ ) and bilateral mPFC (MNI: $x=3$, $y=60, z=-3$ and $x=-3, y=57, z=-3)$. Figure 4A shows brain activity in left ACC (MNI: $x=-3, y=51, z=0$ ) for this contrast. To then examine associations between OXTR rs237887 polymorphisms and brain activity during facial emotion identification of happy vs. angry faces in young and older adults, we conducted follow-up univariate ANOVA collapsed across young and older participants on extracted beta values at the peak voxel of activation. Left ACC activity was greater for AA carriers than GA/GG carriers $\left[F_{(1,51)}=6.51, p=0.014, \eta_{p}^{2}=\right.$ 0.11 ; see Figure 4B]. More interestingly, however, this effect was more pronounced in older than young adults, as tested in univariate ANOVAs conducted separately within young and older participants [Young participants: $F_{(1,23)}=2.38, p=0.136, \eta_{p}^{2}=$ 
0.09; Older participants: $F_{(1,26)}=3.09, p=0.035, \eta_{p}^{2}=0.16$; see Figure 4C]. A comparable pattern of results was found for right $\operatorname{ACC}\left[F_{(1,51)}=6.34, p=0.015, \eta_{p}^{2}=0.11\right]$. In addition, the results for left $\left[F_{(1,51)}=3.24, p=0.078, \eta_{p}^{2}=0.06\right]$ and

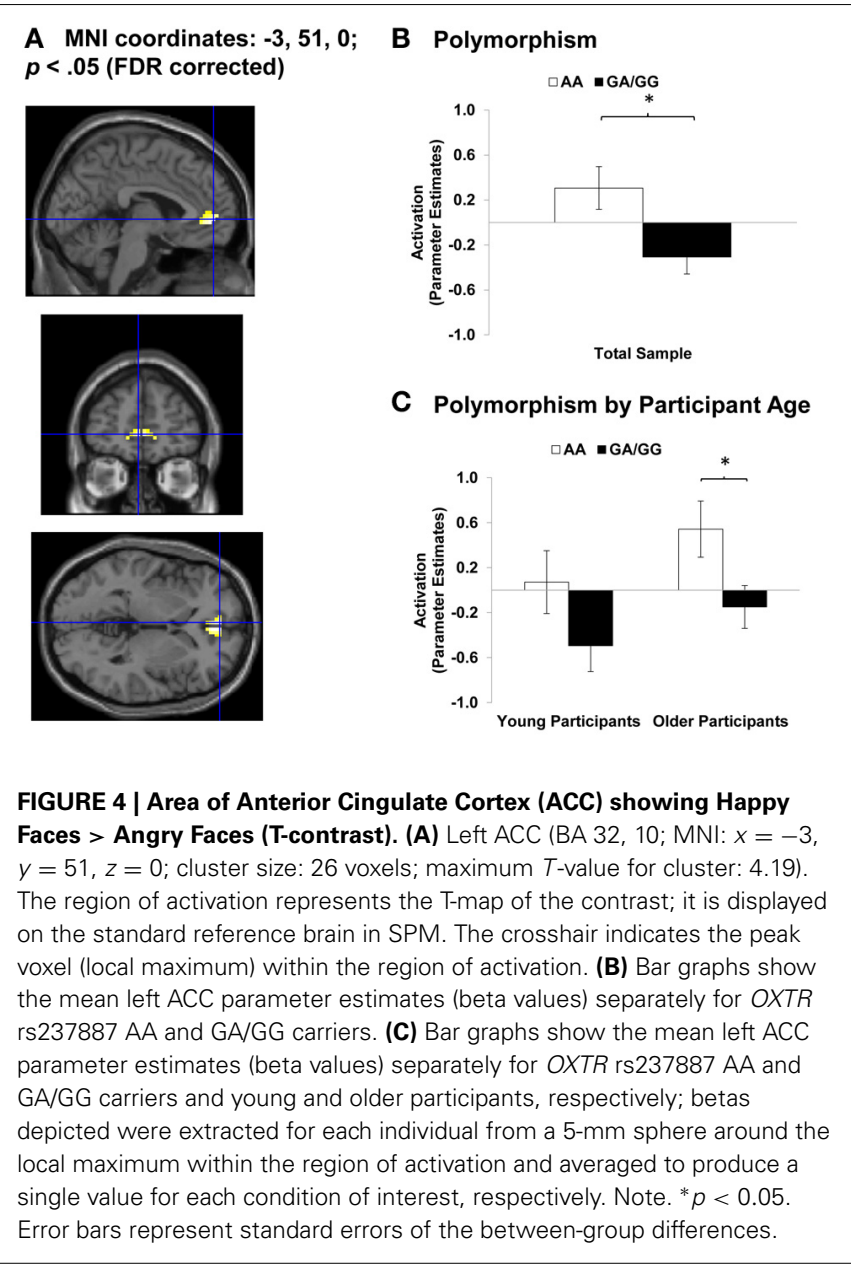

right $\left[F_{(1,51)}=1.29, p=0.261, \eta_{p}^{2}=0.03\right] \mathrm{mPFC}$ pointed in the same direction but were not significant.

ACC is a brain region associated with affective processing (Bush et al., 2000; Amodio and Frith, 2006; Ebner et al., 2012), suggesting that AA compared to GA/GG carriers may process happy compared to angry faces more affectively. This interpretation was further supported by the finding that AA-genotype carriers of OXTR $\mathrm{rs} 237887(M=1111 \mathrm{~ms}, S D=171 \mathrm{~ms})$ were faster at labeling happy expressions than individuals carrying a G-allele $\left[M=1212 \mathrm{~ms}, S D=173 \mathrm{~ms} ; F_{(1,50)}=4.26, p=0.044\right.$, $\left.\eta_{p}^{2}=0.08\right]$, with comparable effects in young and older participants. No comparable effect was found for accuracy in emotion expression identification. However, interestingly, greater recruitment of right ACC in individuals carrying a G-allele was positively correlated $(r=0.35 ; p=0.049)$ with accuracy in reading happy faces but uncorrelated in AA-genotype carriers $(r=0.05$; $p=0.838)$. This suggests that GA/GG carriers, as the group who needed more time on the task, benefitted from recruiting ACC during the facial emotion reading task. This positive brainbehavior correlation in GA/GG carriers was comparable in young and older participants (Fisher's $z=-0.42 ; p=0.337$ ).

For the contrast Angry Faces > Happy Faces, we found greater BOLD response to angry compared to happy faces in left mPFC (MNI: $x=-6, y=15, z=51$ ). In a follow-up univariate ANOVA collapsed across young and older participants on extracted beta values at the peak voxel of activation, activity in left $\mathrm{mPFC}$ did not vary by OXTR rs237887 polymorphism $(p>0.05)$.

To our knowledge this is the first study that considers young and older participants in a genetic-neuro-behavioral examination of facial emotion processing, as suggested in the AGeNeSOT model. Though this secondary data analysis was largely exploratory and replication in a larger independent sample of young and older adults is warranted, our study provides some first indication of a role of OXTR rs 237887 in reading positive compared to negative facial expressions, with some variation as a function of the age of the participant. Intriguingly, OXTR rs237887 has previously been associated with susceptibility for

\section{Box 1 | Questions for future research.}

1. Is aging accompanied by increases or decreases in central and peripheral release of OT?

2. Does the dynamic activity of the OT system change with age and, if so, how and why?

3. Do age-related differences in OT system dynamics underlie age-related differences in socioemotional functioning? If so, how do these changes frame our understanding of the age-associated changes in important social skills (i.e., reading facial emotions, face memory, approach, and avoidance behavior)?

4. How do OT-related individual genetic (and epigenetic) differences interact with neural and behavior age-related changes in socioemotional domains?

5. Does the OT system mediate some of the effects of adverse early experience on health and well-being? How does this play out in old age?

6. Does the OT system mediate some of the salutary psychological and health effects of ongoing social relationships (both intimate and larger social networks)? To what extent do age-related changes in social relationships influence these effects?

7. How do sex differences in OT system dynamics play out in the context of aging? For example, what is the role of age-related changes in estrogen and testosterone?

8. Does the OT system have a role in age-related changes in cognition and memory?

9. Might OT be an effective treatment for conditions like social anxiety or depression in the elderly? Would such treatment improve quality of life?

10. Might older adults be at increased risk of OT-related side effects (i.e., hyponatremia) with chronic dosing? 
ASD (Liu et al., 2010), prosocial behavior (Israel et al., 2009, but see Apicella et al., 2010), and face recognition (Lori et al., 2012). We found improved processing of happy compared to angry faces for AA carriers compared to GA/GG carriers, as reflected in their faster response time in reading happy faces and their increased recruitment of ACC during emotion reading of happy compared to angry faces. Examining young and older participants separately, this increased activation of ACC in AA compared to GA/GG carriers was more pronounced in older than young participants. This is very interesting given broad evidence of preferential processing of positive over negative information in older compared to young adults (Mather and Carstensen, 2005). In addition, our findings suggest that GA/GG carriers' ability to correctly identify happy faces improved when recruiting ACC during the task.

\section{FUTURE TRENDS IN RESEARCH ON OXYTOCIN AND SOCIOEMOTIONAL AGING}

Taken together, this research review indicates that a targeted investigation of age-related changes in the OT system-especially one that considers genetic, neural, and behavioral processeshas the potential to substantively increase our understanding of socioemotional change in aging. We believe that our AGeNeSOT model will be a fruitful conceptual basis in that it raises a set of vital research questions necessary to refine our understanding of OT-related dynamics in aging in socioemotional contexts (see Box 1). In addition, future research along those

\section{REFERENCES}

Adolphs, R. (2003). Cognitive neuroscience of human social behaviour. Nat. Rev. Neurosci. 4, 165-178. doi: 10.1038/nrn1056

Amodio, D. M., and Frith, C. D. (2006). Meeting of the minds: the medial frontal cortex and social cognition. Nat. Rev. Neurosci. 7, 268-277. doi: 10.1038/ nrn 1884

Andari, E., Duhamel, J., Zalla, T., Herbrecht, E., Leboyer, M., and Sirigu, A. (2010). Promoting social behavior with oxytocin in high-functioning autism spectrum disorders. Proc. Natl. Acad. Sci. U.S.A. 107, 4389-4394. doi: 10.1073/pnas.0910249107

Anderson, G. M. (2006). Report of altered urinary oxytocin and AVP excretion in neglected orphans should be reconsidered. J. Autism Dev. Disord. 36, 829-830. doi: 10.1007/s10803-0060153-7

Apicella, C. L., Cesarini, D., Johannesson, M., Dawes, C. T., Lichtenstein, P., and Wallace, B. (2010). No association between oxytocin receptor (OXTR) gene polymorphisms and experimentally elicited social preferences.

lines has great potential to inform both pharmacological and psychosocial interventions targeting social and emotional dysfunction in the elderly. In particular, there is an increasing body of research suggesting a significant role of OT in the context of various disorders characterized by socioemotional dysfunction such as social-bonding deficits or related to social anxiety and stress (Zetzsche et al., 1996; Heinrichs et al., 2003; Taylor et al., 2006; see MacDonald and Feifel, 2012, for an overview), deficits with great relevance in an aging context. Thus, future research toward implementation of pharmacological neuropeptide treatments with the potential to decrease emotional and social stress, anxiety, and depression (Arletti and Bertolini, 1987; Carter and Altemus, 1997) will be important. These interventions may consequently promote positive social interaction and willingness to engage in more frequently rewarding social risks (Heinrichs et al., 2003; Kosfeld et al., 2005), improving health and life quality up until late in life.

\section{ACKNOWLEDGMENTS}

This research was supported in part by the NIH/NCATS Clinical and Translational Science Award to the University of Florida UL1 TR000064 (pilot award to Natalie C. Ebner) and the Swedish Research Council (2008-2356) and the Konung Gustaf V:s och Drottning Victorias Frimurarstiftelse (Håkan Fischer). Some of Kai MacDonald's work was supported by the Goodenough Neuroscience Research Fund. The authors wish to thank Drs. David Feifel and Ronald Cohen for constructive discussions regarding various aspects of this manuscript.

PLoS ONE 5:e11153. doi: Bakermans-Kranenburg, M. J., and van 10.1371/journal.pone.0011153

Arletti, R., Benelli, A., Poggioli, R., Luppi, P., Menozzi, B., and Bertolini, A. (1995). Aged rats are still responsive to the antidepressant and memoryimproving effects of oxytocin. Neuropeptides 29, 177-182. doi: 10.1016/0143-4179(95)90021-7

Arletti, R., and Bertolini, A. (1987). Oxytocin acts as an antidepressant in two animal models of depression. Life Sci. 41, 1725-1730. doi: 10.1016/0024-3205(87)90600-X

Arsenijevic, Y., Dreifuss, J. J., Vallet, P., Marguerat, A., and Tribollet, E. (1995). Reduced binding of oxytocin in the rat brain during aging. Brain Res. 698, 275-279. doi: 10.1016/0006-8993 (95)01020-V

Averbeck, B. B. (2010). Oxytocin and the salience of social cues. Proc. Natl. Acad. Sci. U.S.A. 107, 9033-9034. doi: 10.1073/pnas.1004892107

Bakermans-Kranenburg, M. J., and van IJzendoorn, M. H. (2008). Oxytocin receptor (OXTR) and serotonin transporter (5-HTT) genes associated with observed parenting. Soc. Cogn. Affect. Neurosci. 3, 128-134. doi: 10.1093/scan/nsn004
IJzendoorn, M. H. (2013). Sniffing around oxytocin: review and metaanalyses of trials in healthy and clinical groups with implications for pharmacotherapy. Transl. Psychiatry 3, e258. doi: 10.1038/tp.2013.34

Balleine, B. W., Delgado, M. R., and Hikosaka, O. (2007). The role of the dorsal striatum in reward and decision-making. $J$. Neurosci. 27, 8161-8165. doi: 10.1523/JNEUROSCI.1554-07.2007

Baron-Cohen, S. E., Tager-Flusberg, H. E., and Cohen, D. J. (eds.). (2000). Understanding Other Minds: Perspectives from Developmental Cognitive Neuroscience. New York, NY: Oxford University Press.

Barraza, J., Grewal, N., Ropacki, S., Perez, P., Gonzalez, A., and Zak, P. (2013). Effects of a 10-day oxytocin trial in older adults on health and well-being. Exp. Clin. Psychopharmacol. 21, 85-92. doi: 10.1037/a0031581

Bartlett, J. C., Leslie, J. E., Tubbs, A., and Fulton, A. (1989). Aging and memory for pictures of faces. Psychol. Aging 4, 276-283. doi: 10.1037/0882-7974.4.3.276

Bartz, J. A., Zaki, J., Bolger, N., Hollander, E., Ludwig, N. N.,
Kolevzon, A., et al. (2010). Oxytocin selectively improves empathic accuracy. Psychol. Sci. 21, 1426-1428. doi: 10.1177/0956797610383439

Bartz, J. A., Zaki, J., Bolger, N., and Ochsner, K. N. (2011). Social effects of oxytocin in humans: context and person matter. Trends Cogn. Sci. 15, 301-309. doi: 10.1016/j.tics.2011.05.002

Baumeister, R. F., and Leary, M. R. (1995). The need to belong: desire for interpersonal attachments as a fundamental human motivation. Psychol. Bull. 117, 497. doi: 10.1037/0033-2909.117.3.497

Baumgartner, T., Heinrichs, M., Vonlanthen, A., Fischbacher, U., and Fehr, E. (2008). Oxytocin shapes the neural circuitry of trust and trust adaptation in humans. Neuron 58, 639-650. doi:10.1016/j.neuron.2008.04.009

Blanchard-Fields, F., Mienaltowski, A., and Seay, R. B. (2007). Age differences in everyday problem-solving effectiveness: older adults select more effective strategies for interpersonal problems. J. Gerontol. B Psychol. Sci. Soc. Sci. 62, P61-P64. doi: 10.1093/geronb/62.1.P61

Born, J., Lange, T., Kern, W., McGregor, G. P., Bickel, U., and Fehm, H. 
L. (2002). Sniffing neuropeptides: a transnasal approach to the human brain. Nat. Neurosci. 5, 514-516. doi: $10.1038 / \mathrm{nn} 0602-849$

Brink, T. L., Yesavage, J. A., Lum, O., Heersema, P. H., Adey, M., and Rose, T. L. (1982). Screening tests for geriatric depression. Clin. Gerontol. 1, 37-43. doi: 10.1300/J018v01n01_06

Bush, G., Luu, P., and Posner, M. (2000). Cognitive and emotional influences in anterior cingulate cortex. Trends Cogn. Sci. 4, 215-222. doi: 10.1016/S1364-6613 (00)01483-2

Cacioppo, J. T., Norris, C. J., Decety, J., Monteleone, G., and Nusbaum, H. (2009). In the eye of the beholder: individual differences in perceived social isolation predict regional brain activation to social stimuli. J. Cogn. Neurosci. 21, 83-92. doi: 10.1162/jocn.2009.21007

Calder, A. J., Young, A. W., Keane, J., and Dean, M. (2000). Configural information in facial expression perception. J. Exp. Psychol. Hum. Percept. Perform. 26, 527-551. doi: 10.1037/0096-1523.26.2.527

Carstensen, L. L. (2006). The influence of a sense of time on human development. Science 312, 1913-1915. doi: 10.1126/science. 1127488

Carstensen, L. L., Pasupathi, M., Mayr, U., and Nesselroade, J. R. (2000). Emotional experience in everyday life across the adult life span. J. Pers. Soc. Psychol. 79, 644. doi: 10.1037/0022-3514.79.4.644

Carstensen, L. L., Turan, B., Scheibe, S., Ram, N., Ersner-Hershfield, H., Samanez-Larkin, G. R., et al. (2011). Emotional experience improves with age: evidence based on over 10 years of experience sampling. Psychol. Aging 26, 21-33. doi: $10.1037 / \mathrm{a} 0021285$

Carter, C. S., and Altemus, M. (1997). Integrative functions of lactational hormones in social behavior and stress management. Ann. N.Y. Acad. Sci. 807, 164-174. doi: 10.1111/j.17496632.1997.tb51918.x

Castle, E., Eisenberger, N. I., Seeman, T. E., Moons, W. G., Boggero, I. A., Grinblatt, M. S., et al. (2012). Neural and behavioral bases of age differences in perceptions of trust. Proc. Natl. Acad. Sci. U.S.A. 109, 20848-20852. doi: $10.1073 /$ pnas. 1218518109

Charles, S. T., Reynolds, C. A., and Gatz, M. (2001). Age-related differences and change in positive and negative affect over 23 years. $J$. Pers. Soc. Psychol. 80, 136-151. doi: 10.1037/0022-3514.80.1.136
Choleris, E., Clipperton-Allen, A. E., Phan, A., and Kavaliers, M. (2009). Neuroendocrinology of social information processing in rats and mice. Front. Neuroendocrinol. 30, 442-459. doi: 10.1016/j.yfrne.2009.05.003

Cornwell, E. Y., and Waite, L. J. (2009). Social disconnectedness, perceived isolation, and health among older adults. $J$. Health Soc. Behav. 50, 31-48. doi: 10.1177/002214650905000103

Crook, T. H., Lebowitz, B. D., Pirozzolo, F. J., Zappalà, G., Cavarzeran, F., Measso, G., et al. (1993). Recalling names after introduction: changes across the adult life span in two cultures. Dev. Neuropsychol. 9, 103-113. doi: 10.1080/87565649109540547

Ditzen, B., Schaer, M., Gabriel, B., Bodenmann, G., Ehlert, U., and Heinrichs, M. (2009). Intranasal oxytocin increases positive communication and reduces cortisol levels during couple conflict. Biol. Psychiatry 65, 728-731. doi: 10.1016/j.biopsych. 2008.10.011

Domes, G., Heinrichs, M., Gläscher, J., Büchel, C., Braus, D. F., and Herpertz, S. C. (2007a). Oxytocin attenuates amygdala responses to emotional faces regardless of valence. Biol. Psychiatry 62, 1187-1190. doi: 10.1016/j.biopsych.2007.03.025

Domes, G., Heinrichs, M., Michel, A., Berger, C., and Herpertz, S. C. (2007b). Oxytocin improves "mind-reading" in humans. Biol. Psychiatry 61, 731-733. doi: 10.1016/j.biopsych.2006.07.015

Domes, G., Lischke, A., Berger, C., Grossmann, A., Hauenstein, K., Heinrichs, M., et al. (2010). Effects of intranasal oxytocin on emotional face processing in women. Psychoneuroendocrinology 35, 83-93. doi: 10.1016/j.psyneuen. 2009.06.016

Donaldson, Z. R., and Young, L. J. (2008). Oxytocin, vasopressin, and the neurogenetics of sociality. Science 322, 900-904. doi: 10.1126/science. 1158668

Ebner, N. C., Freund, A. M., and Baltes, P. B. (2006). Developmental changes in personal goal orientation from young to late adulthood: from striving for gains to maintenance and prevention of losses. Psychol. Aging 21, 664-678. doi: 10.1037/0882-7974.21.4.664

Ebner, N. C., Riediger, M., and Lindenberger, U. (2010). FACESA database of facial expressions in young, middle-aged, and older women and men. Development and validation. Behav. Res. Methods. 42, 351-362. doi 10.3758/BRM.42.1.351

Ebner, N. C., He, Y., and Johnson, M. K. (2011). Age and emotion affect how we look at a face: visual scan patterns differ for own-age versus other-age emotional faces. Cogn. Emot. 25, 983-997. doi: 10.1080/02699931.2010.540817

Ebner, N. C., and Johnson, M. K. (2009). Young and older emotional faces: are there age group differences in expression identification and memory? Emotion 9, 329-339. doi: 10.1037/a0015179

Ebner, N. C., and Johnson, M. K. (2010). Age-group differences in interference from young and older emotional faces. Cogn. Emot. 24, 1095-1116. doi: 10.1080/02699930903128395

Ebner, N. C., Johnson, M. K., and Fischer, H. (2012). Neural mechanisms of reading facial emotions in young and older adults. Front. Psychol. 3:223. doi: 10.3389/fpsyg. 2012.00223

Ebner, N. C., Johnson, M. R., Rieckmann, A., Durbin, K. A., Johnson, M. K., and Fischer, H. (2013). Processing own-age vs. other-age faces: neuro-behavioral correlates and effects of emotion. Neuroimage 78, 363-371. doi: $\quad 10.1016 /$ j.neuroimage. 2013.04.029

Ebstein, R. P., Knafo, A., Mankuta, D., Chew, S. H., and Lai, P. S. (2012). The contributions of oxytocin and vasopressin pathway genes to human behavior. Horm. Behav. 61, 359-379. doi: 10.1016/j.yhbeh.2011.12.014

Egawa, J., Watanabe, Y., Endo, T., Tamura, R., Masuzawa, N., and Someya, T. (2012). Association between OXTR and clinical phenotypes of autism spectrum disorders. Psychiatry Res. 208, 99-100. doi: 10.1016/j.psychres.2012.11.007

Feifel, D., MacDonald, K., Cobb, P., and Minassian, A. (2012). Adjunctive intranasal oxytocin improves verbal memory in people with schizophrenia. Schizophr. Res. 139, 207-210. doi: 10.1016/j.schres.2012.05.018

Fekete, E. M., Seay, J., Antoni, M. H., Mendez, A. J., Fletcher, M. A., Szeto, A., et al. (2013). Oxytocin, social support, and sleep quality in lowincome minority women living with HIV. Behav. Sleep Med. 11, 1-15. doi: 10.1080/15402002.2013.791297

Feldman, R., Gordon, I., and ZagoorySharon, O. (2011). Maternal and paternal plasma, salivary, and urinary oxytocin and parent-infant synchrony: considering stress and affiliation components of human bonding. Dev. Sci. 14, 752-761. doi: 10.1111/j.1467-7687.2010.01021.x

Ferrier, B. M., Kennet, D. J., and Devlin, M. C. (1980). Influence of oxytocin on human memory processes. Life Sci. 27, 2311-2317. doi: 10.1016/0024-3205(80)90499-3

Firestone, A. A., Turk-Browne, N. B., and Ryan, J. D. (2007). Age-related deficits in face recognition are related to underlying changes in scanning behavior. Neuropsychol. Dev. Cogn. B Aging Neuropsychol. Cogn. 14, 594-607. doi: 10.1080/13825580600899717

Fischer, H., Nyberg, L., and Bäckman, L. (2010). Age-related differences in brain regions supporting successful encoding of emotional faces. Cortex 46, 490-497. doi: 10.1016/j.cortex.2009.05.011

Fischer, H., Sandblom, J., Gavazzeni, J., Fransson, P., Wright, C. I., and Bäckman, L. (2005). Age-differential patterns of brain activation during perception of angry faces. Neurosi. Lett. 386, 99-104. doi: 10.1016/j.neulet.2005.06.002

Fliers, E., De Vries, G. J., and Swaab, D. F. (1985). Changes with aging in the vasopressin and oxytocin innervation of the rat brain. Brain Res. 348, 1-8. doi: 10.1016/00068993(85)90351-8

Fliers, E., and Swaab, D. F. (1983). Activation of vasopressinergic and oxytocinergic neurons during aging in the wistar rat. Peptides 4, 165-170. doi: 10.1016/0196-9781(83)90108-0

Folstein, M. F., Folstein, S. E., and McHugh, P. R. (1975). Mini-Mental State: A Practical Method for Grading the Cognitive State of Patients for the Clinician. New York, NY: Pergamon Press.

Freund, A. M. (2006). Age-differential motivational consequences of optimization versus compensation focus in younger and older adults. Psychol. Aging 21, 240-252. doi: 10.1037/0882-7974. 21.2.240

Fries, A. B. W., Ziegler, T. E., Kurian, J. R., Jacoris, S., and Pollak, S. D. (2005). Early experience in humans is associated with changes in neuropeptides critical for regulating social behavior. Proc. Natl. Acad. Sci. U.S.A. 102, 17237-17240. doi: 10.1073/pnas.0504767102

Gabor, C. S., Phan, A., ClippertonAllen, A., Kavaliers, M., and Choleris, E. (2012). Interplay of oxytocin, vasopressin, and sex hormones in the regulation of 
social recognition. Behav. Neurosci. 126, 97-109. doi: 10.1037/a00 26464

Gamer, M., Zurowski, B., and Büchel, C. (2010). Different amygdala subregions mediate valence-related and attentional effects of oxytocin in humans. Proc. Natl. Acad. Sci. U.S.A. 107, 9400-9405. doi: 10.1073/pnas.1000985107

Gimpl, G., and Fahrenholz, F. (2001). The oxytocin receptor system: structure, function, and regulation. Physiol. Rev. 81, 629-683.

Gottfries, C. G. (1997). Recognition and management of depression in the elderly. Int. Clin. Psychopharmacol. 12, S31-S36. doi: 10.1097/0000 4850-199712007-00006

Gouin, J., Carter, C. S., PournajafiNazarloo, H., Glaser, R., Malarkey, W. B., Loving, T. J., et al. (2010). Marital behavior, oxytocin, vasopressin, and wound healing. Psychoneuroendocrinology 35, 1082-1090. doi: $10.1016 / \mathrm{j}$. psyneuen.2010.01.009

Grady, C. L. (2008). Cognitive neuroscience of aging. Ann. N.Y. Acad. Sci. 1124, 127-144. doi: 10.1196/annals. 1440.009

Grady, C. L., and Keightley, M. L. (2002). Studies of altered social cognition in neuropsychiatric disorders using functional neuroimaging. Can. J. Psychiatry 47, 327-336.

Grady, C. L., McIntosh, A. R., Horwitz, B., Maisog, J. M., Ungerleider, L. G., Mentis, M. J., et al. (1995). Age-related reductions in human recognition memory due to impaired encoding. Science 269, 218-221. doi: 10.1126/science. 7618082

Groppe, S. E., Gossen, A., Rademacher, L., Hahn, A., Westphal, L., Gründer, G., et al. (2013). Oxytocin influences processing of socially relevant cues in the ventral tegmental area of the human brain. Biol. Psychiatry 74, 172-179. doi: 10.1016/j.biopsych. 2012.12 .023

Gross, J. J., and Levenson, R. W. (1997). Hiding feelings: the acute effects of inhibiting negative and positive emotion. J. Abnorm. Psychol. 106, 95-103. doi: 10.1037/0021843X.106.1.95

Guastella, A., Alvares, G., Hickie, I., Chan, H., Chen, T., and Banati, R. (2013). Unitary hormonal models, peripheral markers, and evaluation of response to drug: a response to Weisman and Feldman. Psychoneuroendocrinology 38,
627-628. doi: 10.1016/j.psyneuen. 2013.03.005

Guastella, A. J., Carson, D. S., Dadds, M. R., Mitchell, P. B., and Cox, R. E. (2009). Does oxytocin influence the early detection of angry and happy faces? Psychoneuroendocrinology 34, 220-225. doi: 10.1016/j.psyneuen. 2008.09.001

Guastella, A. J., Einfeld, S. L., Gray, K. M., Rinehart, N. J., Tonge, B. J., Lambert, T. J., et al. (2010). Intranasal oxytocin improves emotion recognition for youth with autism spectrum disorders. Biol. Psychiatry 67, 692-694. doi: 10.1016/j.biopsych. 2009.09.020

Guastella, A. J., Mitchell, P. B., and Dadds, M. R. (2008). Oxytocin increases gaze to the eye region of human faces. Biol. Psychiatry 63, 3-5. doi: 10.1016/j.biopsych. 2007.06.026

Gunning-Dixon, F., Gur, R. C., Perkins, A. C., Schroeder, L., Turner, T., Turetsky, B. I., et al. (2003). Aged-related differences in brain activation during emotional face processing. Neurobiol. Aging 24, 285-295. doi: 10.1016/S0197-4580 (02)00099-4

Haxby, J. V., Hoffman, E. A., and Gobbini, M. I. (2000). The distributed human neural system for face perception. Trends Cogn. Sci. 4, 223-233. doi: 10.1016/S13646613(00)01482-0

Haxby, J. V., Hoffman, E. A., and Gobbini, M. I. (2002). Human neural systems for face recognition and social communication. Biol. Psychiatry 51, 59-67. doi: 10.1016/S0006-3223 (01)01330-0

Heim, C., Young, L. J., Newport, D. J., Mletzko, T., Miller, A. H., and Nemeroff, C. B. (2008). Lower CSF oxytocin concentrations in women with a history of childhood abuse. Mol. Psychiatry 14, 954-958. doi: 10.1038/mp. 2008.112

Heinrichs, M., Baumgartner, T., Kirschbaum, C., and Ehlert, U. (2003). Social support and oxytocin interact to suppress cortisol and subjective responses to psychosocial stress. Biol. Psychiatry 54, 1389-1398. doi: $10.1016 / \mathrm{S} 0006-3223$ (03)00465-7

Heinrichs, M., Meinlschmidt, G., Wippich, W., Ehlert, U., and Hellhammer, D. H. (2004). Selective amnesic effects of oxytocin on human memory. Physiol. Behav. 83, 31-38. doi: 10.1016/j.physbeh. 2004.07.020
Huber, D., Veinante, P., and Stoop, R. (2005). Vasopressin and oxytocin excite distinct neuronal populations in the central amygdala. Science 308, 245-248. doi: 10.1126/science. 1105636

Huffmeijer, R., van IJzendoorn, M. H., and Bakermans-Kranenburg, $M$. J. (2012). Ageing and oxytocin: a call for extending human oxytocin research to ageing populations - a mini-review. Gerontology 59, 32-39. doi: 10.1159/000341333

Iidaka, T., Okada, T., Murata, T., Omori, M., Kosaka, H., Sadato, N., et al. (2002). Age-related differences in the medial temporal lobe responses to emotional faces as revealed by fMRI. Hippocampus 12, 352-362. doi: 10. 1002/hipo.1113

Insel, T. R. (2010). The challenge of translation in social neuroscience: a review of oxytocin, vasopressin, and affiliative behavior. Neuron 65 , 768-779. doi: 10.1016/j.neuron. 2010.03.005

Insel, T. R., and Fernald, R. D. (2004). How the brain processes social information: searching for the social brain. Annu. Rev. Neurosci. 27, 697-722. doi: 10.1146/annurev. neuro.27.070203.144148

Isaacowitz, D. M., Löckenhoff, C. E. Lane, R. D., Wright, R., Sechrest, L., Riedel, R., et al. (2007). Age differences in recognition of emotion in lexical stimuli and facial expressions. Psychol. Aging 22, 147-159. doi: 10.1037/0882-7974. 22.1.147

Isaacowitz, D. M., Wadlinger, $\mathrm{H}$. A., Goren, D., and Wilson, $\mathrm{H}$ R. (2006). Selective preference in visual fixation away from negative images in old age? An eye-tracking study. Psychol. Aging 21, 40-48. doi: 10.1037/0882-7974. 21.1.40

Israel, S., Knafo, A., Ebstein, R. P., Lerer, E., Shalev, I., and Uzefovsky, F. (2009). The oxytocin receptor (OXTR) contributes to prosocial fund allocations in the dictator game and the social value orientations task. PLoS ONE 4:e5535. doi: 10.1371/journal.pone.0005535

Keck, M. E., Hatzinger, M., Wotjak, C. T., Landgraf, R., Holsboer, F., and Neumann, I. D. (2000). Ageing alters intrahypothalamic release patterns of vasopressin and oxytocin in rats. Eur. J. Neurosci. 12 1487-1494.

Keightley, M. L., Chiew, K. S., Winocur, G., and Grady, C. L. (2007). Agerelated differences in brain activity underlying identification of emotional expressions in faces. Soc.
Cogn. Affect. Neurosci. 2, 292-302. doi: 10.1093/scan/nsm024

Kemp, A. H., and Guastella, A. J. (2010). Oxytocin: prosocial behavior, social salience, or approachrelated behavior? Biol. Psychiatry 67, e33-e34. doi: 10.1016/j.biopsych. 2009.11.019

Kéri, S., and Kiss, I. (2011). Oxytocin response in a trust game and habituation of arousal. Physiol. Behav. 102, 221-224. doi: 10.1016/j.physbeh. 2010.11.011

Kessler, E., and Staudinger, U. (2009). Affective experience in adulthood and old age: the role of affective arousal and perceived affect regulation. Psychol. Aging 24, 349-362. doi: 10.1037/a0015352

Kimura, T., Tanizawa, O., Mori, K., Brownstein, M. J., and Okayama, H. (1992). Structure and expression of a human oxytocin receptor. Nature 356, 526-529. doi: $10.1038 / 356526 \mathrm{a} 0$

Kirchner, W. K. (1958). Age differences in short-term retention of rapidly changing information. J. Exp. Psychol. 55, 352-358. doi: 10.1037/h0043688

Kirsch, P., Esslinger, C., Chen, Q., Mier, D., Lis, S., Siddhanti, S. et al. (2005). Oxytocin modulates neural circuitry for social cognition and fear in humans. J. Neurosci. 25, 11489-11493. doi: 10.1523/JNEUROSCI.3984-05.2005

Kiss, I., Levy-Gigi, E., and Kéri, S. (2011). CD 38 expression, attachment style and habituation of arousal in relation to trust-related oxytocin release. Biol. Psychol. 88, 223-226. doi: 10.1016/j.biopsycho. 2011.08.005

Knobloch, H. S., Charlet, A., Hoffmann, L. C., Eliava, M., Khrulev, S., Cetin, A. H., et al. (2012). Evoked axonal oxytocin release in the central amygdala attenuates fear response. Neuron 73, 553-566. doi: 10.1016/j.neuron. 2011.11.030

Kogan, A., Saslow, L. R., Impett, E. A., Oveis, C., Keltner, D., and Saturn, S. R. (2011). Thin-slicing study of the oxytocin receptor (OXTR) gene and the evaluation and expression of the prosocial disposition. Proc. Natl. Acad. Sci. U.S.A. 108 19189-19192. doi: 10.1073/pnas. 1112658108

Kosfeld, M., Heinrichs, M., Zak, P. J., Fischbacher, U., and Fehr, E. (2005). Oxytocin increases trust in humans. Nature 435, 673-676. doi: 10.1038/nature03701

Kumsta, R., Chen, F. S., Pape, H., and Heinrichs, M. (2013). Neuropeptide $\mathrm{S}$ receptor gene is associated with 
cortisol responses to social stress in humans. Biol. Psychol. 93, 304-307. doi: 10.1016/j.biopsycho. 2013.02.018

Kunzmann, U., Kupperbusch, C. S., and Levenson, R. W. (2005). Behavioral inhibition and amplification during emotional arousal: a comparison of two age groups. Psychol. Aging 20, 144-158. doi: 10.1037/08827974.20.1.144

Labuschagne, I., Phan, K. L., Wood, A., Angstadt, M., Chua, P., and Heinrichs, M. (2010). Oxytocin attenuates amygdala reactivity to fear in generalized social anxiety disorder. Neuropsychopharmacology 35, 2403-2413. doi: 10.1038/npp. 2010.123

Landgraf, R., and Neumann, I. D. (2004). Vasopressin and oxytocin release within the brain: a dynamic concept of multiple and variable modes of neuropeptide communication. Front. Neuroendocrinol. 25, 150-176. doi: 10.1016/j.yfrne. 2004.05.001

Lawton, M., Kleban, M., Rajagopal, D., and Dean, J. (1992). Dimensions of affective experience in three age groups. Psychol. Aging 7, 171-184. doi: 10.1037//0882-7974. 7.2.171

Leng, G., and Ludwig, M. (2006). Information processing in the hypothalamus: peptides and analogue computation. $J$. Neuroendocrinol. 18, 379-392. doi: 10.1111/j.1365-2826.2006.01428.x

Lerer, E., Levi, S., Salomon, S., Darvasi, A., Yirmiya, N., and Ebstein, R. P. (2008). Association between the oxytocin receptor (OXTR) gene and autism: relationship to Vineland adaptive behavior scales and cognition. Mol. Psychiatry 13, 980-988. doi: 10.1038/sj.mp.4002087

Lezak, M. D. (1995). Neuropsychological Assessment, 3rd Edn. New York, NY: Oxford University Press.

Lischke, A., Berger, C., Prehn, K., Heinrichs, M., Herpertz, S. C., and Domes, G. (2011). Intranasal oxytocin enhances emotion recognition from dynamic facial expressions and leaves eye-gaze unaffected. Psychoneuroendocrinology 37, 475-481. doi: 10.1016/j.psyneuen. 2011.07.015

List, J. A. (2004). Young, selfish and male: field evidence of social preferences. Econ. J. 114, 121-149. doi: 10.1046/j.0013-0133. 2003.00180.x

Liu, X., Kawamura, Y., Shimada, T., Otowa, T., Koishi, S., Sugiyama, T., et al. (2010). Association of the oxytocin receptor (OXTR) gene polymorphisms with autism spectrum disorder (ASD) in the Japanese population. J. Hum. Genet. 55, 137-141. doi: 10.1038/jhg.2009.140

Lori, A., Lee, I., Cubells, J. F., Binder, E. B., Lehtimäki, T., Puura, K., et al. (2012). "Single nucleotide polymorphism (SNP) fine mapping of the AVPR1A and OXTR loci reveals an OXTR association with a social memory endophenotype in probands with autism and their family members," in Conference Presentation at American Society of Human Genetics (San Fransisco, CA).

Loup, F., Tribollet, E., DuboisDauphin, M., and Dreifuss, J. J. (1991). Localization of high-affinity binding sites for oxytocin and vasopressin in the human brain: an autoradiographic study. Brain Res. 555, 220-232. doi: 10.1016/0006-8993 (91) $90345-\mathrm{V}$

Lucht, M. J., Barnow, S., Sonnenfeld, C., Rosenberger, A., Grabe, H. J., Schroeder, W., et al. (2009). Associations between the oxytocin receptor gene (OXTR) and affect, loneliness and intelligence in normal subjects. Prog. Neuropsychopharmacol. Biol. Psychiatry 33, 860-866. doi: 10.1016/j.pnpbp.2009.04.004

MacDonald, K. (2012). Sex, receptors, and attachment: a review of individual factors influencing response to oxytocin. Front. Neurosci. 6:194. doi: 10.3389/fnins.2012.00194

MacDonald, K., and Feifel, D. (2012). Oxytocin in schizophrenia: a review of evidence for its therapeutic effects. Acta Neuropsychiatr. 24, 130-146. doi: 10.1111/j.1601-5215.2011.00634.x

MacDonald, K., and Feifel, D. (2013). Helping oxytocin deliver: considerations in the development of oxytocin-based therapeutics for brain disorders. Front. Neurosci. 7, 1-20. doi: 10.3389/fnins.2013.00035

Magai, C., Consedine, N., Krivoshekova, Y., Kudadjie-Gyamfi, E., and McPherson, R. (2006). Emotion experience and expression across the adult life span: insights from a multimodal assessment study. Psychol. Aging 21, 303-317. doi: 10.1037/0882-7974.21.2.303

Marsh, A., Yu, H., Pine, D., and Blair, R. (2010). Oxytocin improves specific recognition of positive facial expressions. Psychopharmacology 209, 225-232. doi: 10.1007/s00213-010-1780-4

Mather, M., and Carstensen, L. L. (2005). Aging and motivated cognition: the positivity effect in attention and memory.
Trends Cogn. Sci. 9, 496-502. doi: 10.1016/j.tics.2005.08.005

Meinlschmidt, G., and Heim, C. (2007). Sensitivity to intranasal oxytocin in adult men with early parental separation. Biol. Psychiatry 61, 1109-1111. doi: 10.1016/j.biopsych.2006.09.007

Melis, M. R., Mauri, A., and Argiolas, A. (1995). Opposite changes in the content of oxytocin- and vasopressin-like immunoreactive peptides in the rat thymus during aging. Regul. Pept. 59, 335-340. doi: 10.1016/0167-0115(95)00088-S

Melis, M. R., Spano, M. S., Succu, S., and Argiolas, A. (1999). The oxytocin antagonist $\mathrm{d}(\mathrm{CH} 2) 5 \mathrm{Tyr}(\mathrm{Me}) 2$-Orn8-vasotocin reduces non-contact penile erections in male rats. Neurosci. Lett. $\quad 265$, 171-174. doi: 10.1016/S0304-3940(99)00236-0

Melis, M. R., Stancampiano, R., Fratta, W., and Argiolas, A. (1992). Oxytocin concentration changes in different rat brain areas but not in plasma during aging. Neurobiol. Aging 13, 783-786. doi: 10.1016/0197-4580(92)90102-4

Meyer-Lindenberg, A., Domes, G. Kirsch, P., and Heinrichs, M. (2011). Oxytocin and vasopressin in the human brain: social neuropeptides for translational medicine. Nat. Rev. Neurosci. 12, 524-538. doi: 10.1038/nrn3044

Mikolajczak, M., Pinon, N., Lane, A., de Timary, P., and Luminet, O. (2010). Oxytocin not only increases trust when money is at stake, but also when confidential information is in the balance. Biol. Psychol. 85, 182-184. doi: 10.1016/j.biopsycho.2010.05.010

Nielsen, L., and Mather, M. (2011). Emerging perspectives in social neuroscience and neuroeconomics of aging. Soc. Cogn. Affect. Neurosci. 6, 149-164. doi: 10.1093/scan/nsr019

Norman, G. J., Cacioppo, J. T., Morris, J. S., Karelina, K., Malarkey, W. B., DeVries, A. C., et al. (2011). Selective influences of oxytocin on the evaluative processing of social stimuli. $J$. Psychopharmacol. 25, 1313-1319. doi: $10.1177 / 0269881110367452$

Parker, K. J., Hoffman, C. L., Hyde, S. A., Cummings, C. S., and Maestripieri, D. (2010). Effects of age on cerebrospinal fluid oxytocin levels in free-ranging adult female and infant rhesus macaques. Behav. Neurosci. 124, 428-433. doi: 10.1037/a0019576

Pedersen, C. A., Caldwell, J. D., Walker, C., Ayers, G., and Mason, G. A. (1994). Oxytocin activates the postpartum onset of rat maternal behavior in the ventral tegmental and medial preoptic areas. Behav. Neurosci. 108, 1163. doi: 10.1037/0735-7044.108.6.1163

Pessoa, L., and Adolphs, R. (2010). Emotion processing and the amygdala: from a 'low road' to 'many roads' of evaluating biological significance. Nat. Rev. Neurosci. 11, 773-783. doi: 10.1038/nrn2920

Petrovic, P., Kalisch, R., Singer, T., and Dolan, R. J. (2008). Oxytocin attenuates affective evaluations of conditioned faces and amygdala activity. J. Neurosci. 28, 6607-6615. doi: 10.1523/JNEUROSCI.4572-07.2008

Phan, K. L., Sripada, C. S., Angstadt, M., and McCabe, K. (2010). Reputation for reciprocity engages the brain reward center. Proc. Natl. Acad. Sci. U.S.A. 107, 13099-13104. doi: 10.1073/pnas. 1008137107

Phillips, L. H., Henry, J. D., Hosie, J. A., and Milne, A. B. (2008). Effective regulation of the experience and expression of negative affect in old age. J. Gerontol. Series B Psychol. Sci. Soc. Sci. 63, P138-P145. doi: 10.1093/geronb/63.3.P138

Quinn, R. (2005). Comparing rat's to human's age: how old is my rat in people years? Nutrition 21, 775-777. doi: 10.1016/j.nut.2005.04.002

Raz, N. (2005). "The aging brain observed in vivo: differential changes and their modifiers," in Cognitive Neuroscience of Aging: Linking Cognitive and Cerebral Aging, eds R. Cabeza, L. Nyberg, and D. Park (New York, NY: Oxford University Press), 19-57.

Raz, N., Lindenberger, U., Rodrigue, K. M., Kennedy, K. M., Head, D., Williamson, A., et al. (2005). Regional brain changes in aging healthy adults: general trends, individual differences and modifiers. Cereb. Cortex 15, 1676-1689. doi: 10.1093/cercor/bhi044

Riediger, M., Schmiedek, F., Wagner, G. G., and Lindenberger, U. (2009). Seeking pleasure and seeking pain: differences in prohedonic and contra-hedonic motivation from adolescence to old age. Psychol. Sci. 20, 1529-1535. doi: 10.1111/j.1467-9280.2009.02473.x

Riedl, R., and Javor, A. (2011). The biology of trust: integrating evidence from genetics, endocrinology, and functional brain imaging. J. Neurosci. Psychol. Econ. 5, 63-91. doi: 10.1037/a0026318

Riem, M. M., Bakermans-Kranenburg, M. J., Pieper, S., Tops, M., Boksem, M. A., Vermeiren, R. R., et al. (2011). Oxytocin modulates 
amygdala, insula, and inferior frontal gyrus responses to infant crying: a randomized controlled trial. Biol. Psychiatry 70, 291-297. doi: 10.1016/j.biopsych. 2011.02.006

Rimmele, U., Hediger, K., Heinrichs, M., and Klaver, P. (2009). Oxytocin makes a face in memory familiar. J. Neurosci. 29, 38-42. doi: 10.1523/JNEUROSCI.4260-08.2009

Rockliff, H., Karl, A., McEwan, K., Gilbert, J., Matos, M., and Gilbert, P. (2011). Effects of intranasal oxytocin on 'compassion focused imagery'. Emotion 11, 1388-1396. doi: 10.1037/a0023861

Rodrigues, S. M., Saslow, L. R., Garcia, N., John, O. P., and Keltner, D. (2009). Oxytocin receptor genetic variation relates to empathy and stress reactivity in humans. Proc. Natl. Acad. Sci. U.S.A. 106, 21437-21341. doi: 10.1073/pnas.0909579106

Ruffman, T., Henry, J. D., Livingstone, V., and Phillips, L. H. (2008). A meta-analytic review of emotion recognition and aging: implications for neuropsychological models of aging. Neurosci. Biobehav. Rev. 32, 863-881. doi: 10.1016/j.neubiorev.2008.01.001

Ruffman, T., Murray, J., Halberstadt, J., and Vater, T. (2012). Age-related differences in deception. Psychol. Aging 27, 543-549. doi: $10.1037 /$ a0023380

Samanez-Larkin, G. R., and Carstensen, L. L. (2011). "Socioemotional functioning and the aging brain," in The Handbook of Social Neuroscience, eds J. Decety and J. T. Cacioppo (New York, NY: Oxford University Press), 507-523.

Sauer, C., Montag, C., Reuter, M., and Kirsch, P. (2013). Imaging oxytocin $\mathrm{x}$ dopamine interactions: an epistasis effect of CD38 and COMT gene variants influences the impact of oxytocin on amygdala activation to social stimuli. Front. Neurosci. 7:45. doi: 10.3389/fnins. 2013.00045

Sauer, C., Montag, C., Worner, C., Kirsch, P., and Reuter, M. (2012). Effects of a common variant in the $\mathrm{CD} 38$ gene on social processing in an oxytocin challenge study: possible links to autism. Neuropsychopharmacology 37, 1474-1482. doi: 10.1038/npp.2011. 333

Savaskan, E., Ehrhardt, R., Schulz, A., Walter, M., and Schächinger, $\mathrm{H}$. (2008). Post-learning intranasal oxytocin modulates human memory for facial identity. Psychoneuroendocrinology 33,
368-374. doi: 10.1016/j.psyneuen. 2007.12.004

Scheele, D., Striepens, N., Güntürkün, O., Deutschländer, S., Maier, W., Kendrick, K. M., et al. (2012). Oxytocin modulates social distance between males and females. J. Neurosci. 32, 16074-16079. doi: 10.1523/JNEUROSCI.275512.2012

Scheele, D. A., Scheele, D., Wille, A., Kendrick, K. M., Becker, B., Güntürkün, O., et al. (2013). Oxytocin alters the human reward system to maintain romantic love [Abstract]. Biol. Psychiatry 73, 95S-95S.

Scheibe, S., and Blanchard-Fields, F. (2009). Effects of regulating emotions on cognitive performance: what is costly for young adults is not so costly for older adults. Psychol. Aging 24, 217-223. doi: 10.1037/a0013807

Scheibe, S., and Carstensen, L. L. (2010). Emotional aging: recent findings and future trends. $J$. Gerontol. Series B Psychol. Sci. Soc. Sci. 65B, 135-144. doi: 10.1093/geronb/gbp132

Schneiderman, I., Zagoory-Sharon, O., Leckman, J. F., and Feldman, R. (2012). Oxytocin during the initial stages of romantic attachment: relations to couples' interactive reciprocity. Psychoneuroendocrinology 37, 1277-1285. doi: 10.1016/j. psyneuen.2011.12.021

Shahrestani, S., Kemp, A. H., and Guastella, A. J. (2013). The impact of a single administration of intranasal oxytocin on the recognition of basic emotions in humans: a meta-analysis. Neuropsychopharmacology. doi: 10.1038/npp.2013.86. [Epub ahead of print].

Shamay-Tsoory, S. G. (2010). One hormonal system for love and envy: a reply to tops. Biol. Psychiatry 67, e7. doi: 10.1016/j.biopsych.2009. 09.002

Shamay-Tsoory, S. G., Fischer, M., Dvash, J., Harari, H., PerachBloom, N., and Levkovitz, Y. (2009). Intranasal administration of oxytocin increases envy and schadenfreude (gloating). Biol. Psychiatry 66, 864-870. doi: 10.1016/j.biopsych.2009.06.009

Singer, T., Snozzi, R., Bird, G., Petrovic, P., Silani, G., Heinrichs, M., et al. (2008). Effects of oxytocin and prosocial behavior on brain responses to direct and vicariously experienced pain. Emotion 8, 781-791. doi: 10.1037/a0014195

Spielberger, C. D., Gorsuch, R. L., and Lushene, R. F. (1970).
Manual for the State-Trait Anxiety Inventory. Palo Alto, CA: Consulting Psychologist Press.

St. Jaques, P. L., Winecoff, A., and Cabeza, R. (2013). "Emotion and aging," in The Cambridge Handbook of Human Affective Neuroscience, eds J. Armony and P. Vuilleumier (Cambridge, MA: Cambridge University Press), 635-661.

Tansey, K. E., Brookes, K. J., Hill, M. J., Cochrane, L. E., Gill, M., Skuse, D., et al. (2010). Oxytocin receptor (OXTR) does not play a major role in the aetiology of autism: genetic and molecular studies. Neurosci. Lett. 474, 163-167. doi: 10.1016/j.neulet. s2010.03.035

Taylor, S. E., Gonzaga, G. C., Klein, L. C., Hu, P., Greendale, G. A., and Seeman, T. E. (2006). Relation of oxytocin to psychological stress responses and hypothalamicpituitary-adrenocortical axis activity in older women. Psychosom. Med. 68, 238-245. doi: 10.1097/01. psy.0000203242.95990.74

Teachman, B. A. (2006). Aging and negative affect: the rise and fall and rise of anxiety and depression symptoms. Psychol. Aging 21, 201. doi: 10.1037/0882-7974.21. 1.201

Tessitore, A., Hariri, A. R., Fera, F., Smith, W. G., Das, S., Weinberger, D. R., et al. (2005). Functional changes in the activity of brain regions underlying emotion processing in the elderly. Psychiatry Res. Neuroimaging 139, 9-18. doi: $\quad 10.1016 / j . p s c y c h r e s n s$. 2005.02.009

Theodoridou, A., Rowe, A. C., PentonVoak, I. S., and Rogers, P. J. (2009). Oxytocin and social perception: oxytocin increases perceived facial trustworthiness and attractiveness. Horm. Behav. 56, 128-132. doi: 10.1016/j.yhbeh. 2009.03.019

Tops, M. (2009). Oxytocin: envy or engagement in others? Biol. Psychiatry 67, e5-e6. doi: 10.1016/j.biopsych.2009.08.032

Van Anders, S. M., Goldey, K. L., and Kuo, P. X. (2011). The steroid/peptide theory of social bonds: integrating testosterone and peptide responses for classifying social behavioral contexts. Psychoneuroendocrinology 36, 1265-1275. doi: 10.1016/ j.psyneuen.2011.06.001

Van IJzendoorn, M. H., and Bakermans-Kranenburg, M. J. (2012). A sniff of trust: metaanalysis of the effects of intranasal oxytocin administration on face recognition, trust to ingroup, and trust to out-group. Psychoneuroendocrinology 37, 438-443. doi: 10.1016/j.psyneuen. 2011.07.008

Verhaeghen, P., and Salthouse, T. (1997). Meta-analyses of agecognition relations in adulthood: estimates of linear and nonlinear age effects and structural models. Psychol. Bull. 122, 231-249. doi: 10.1037/0033-2909.122.3.231

Viviani, D., Charlet, A., van den Burg, E., Robinet, C., Hurni, N., Abatis, M., et al. (2011). Oxytocin selectively gates fear responses through distinct outputs from the central amygdala. Science 333, 104-107. doi: 10.1126/science. 1201043

Voelkle, M., Ebner, N., Lindenberger, U., and Riediger, M. (2013). Here we go again: anticipatory and reactive mood responses to recurring unpleasant situations throughout adulthood. Emotion 13, 424-433. doi: $10.1037 / \mathrm{a} 0031351$

Walum, H., Lichtenstein, P., Neiderhiser, J. M., Reiss, D., Ganiban, J. M., Spotts, E. L., et al. (2012). Variation in the oxytocin receptor gene is associated with pair-bonding and social behavior. Biol. Psychiatry 71, 419-426. doi: 10.1016/j.biopsych. 2011.09.002

Weisman, O., and Feldman, R. (2013). Oxytocin administration affects the production of multiple hormones. Psychoneuroendocrinology 38 626-627. doi: 10.1016/j.psyneuen. 2013.03.004

Westberg, L., and Walum, H. (2013). "Oxytocin and vasopressin gene variation and the neural basis of prosocial behavior," in The Oxford Handbook of Molecular Psychology, ed T. Canli (New York, NY: Oxford University Press).

Wierda, M., Goudsmit, E., van der Woude, P., Purba, J., Hofman, M., Bogte, H., et al. (1991). Oxytocin cell number in the human paraventricular nucleus remains constant with aging and in Alzheimer's disease. Neurobiol. Aging 12, 511-516. doi: 10.1016/0197-4580 (91)90081-T

Williams, L. M., Brown, K. J., Palmer, D., Liddell, B. J., Kemp, A. H., Olivieri, G., et al. (2006). The mellow years?: neural basis of improving emotional stability over age. J. Neurosci. 26, 6422-6430. doi: $\quad 10.1523 /$ JNEUROSCI 0022-06.2006

Winslow, J., Noble, P., Lyons, C., Sterk, S., and Insel, T. (2003). Rearing effects on cerebrospinal fluid oxytocin concentration and 
social buffering in rhesus monkeys. Neuropsychopharmacology 28, 910-918. doi: 10.1038/sj.npp. 1300128

Wittfoth-Schardt, D., Grunding, J., Wittfoth, M., Lanfermann, H., Heinrichs, M., Domes, G., et al. (2012). Oxytocin modulates neural reactivity to children's faces as a function of social salience. Neuropsychopharmacology 37, 1799-1807. doi: 10.1038/npp. 2012.47

Wright, C. I., Wedig, M. M., Williams, D., Rauch, S. L., and Albert, M. S. (2006). Novel fearful faces activate the amygdala in healthy young and elderly adults. Neurobiol. Aging 27, 361-374. doi: $\quad 10.1016 /$ j.neurobiolaging. 2005.01.014

Yoshida, M., Takayanagi, Y., Inoue, K., Kimura, T., Young, L. J., Onaka, T., et al. (2009). Evidence that oxytocin exerts anxiolytic effects via oxytocin receptor expressed in serotonergic neurons in mice. J. Neurosci. 29, 2259-2271. doi: 10.1523/JNEUROSCI.559308.2009

Yu, K.-L., Tamada, Y., Suwa, F., Fang, Y.-R., and Tang, C.-S. (2006). Agerelated changes in oxytocin-, arginine vasopressin- and nitric oxide synthase-expressing neurons in the supraoptic nucleus of the rat. Life Sci. 78, 1143-1148.

Zak, P. J., Kurzban, R., and Matzner, W. T. (2005). Oxytocin is associated with human trustworthiness. Horm. Behav. 48, 522-527. doi: 10.1016/j.yhbeh. 2005.07.009

Zbuzek, V., Fuchs, A., Zbuzek, V. K., and Wu, W. (1988). Neurohypophyseal aging: differential changes in oxytocin and vasopressin release, studied in
Fischer 344 and Sprague-Dawley rats. Neuroendocrinology 48, 619-626. doi: 10.1159/000125072

Zetzsche, T., Frasch, A., Jirikowski, G., Murck, H., and Steiger, A. (1996). Nocturnal oxytocin secretion is reduced in major depression. Biol. Psychiatry 39, 584. doi: 10.1016/0006-3223(96) $84235-1$

Zink, C. F., and Meyer-Lindenberg, A. (2012). Human neuroimaging of oxytocin and vasopressin in social cognition. Horm. Behav. 61, 400-409. doi: 10.1016/j.yhbeh.2012.01.016

Conflict of Interest Statement: The authors declare that the research was conducted in the absence of any commercial or financial relationships that could be construed as a potential conflict of interest.
Received: 28 May 2013; accepted: 01 August 2013; published online: 28 August 2013.

Citation: Ebner NC, Maura GM, MacDonald K, Westberg L and Fischer $H$ (2013) Oxytocin and socioemotional aging: Current knowledge and future trends. Front. Hum. Neurosci. 7:487. doi: 10.3389/fnhum.2013.00487

This article was submitted to the journal Frontiers in Human Neuroscience.

Copyright (C) 2013 Ebner, Maura, MacDonald, Westberg and Fischer. This is an open-access article distributed under the terms of the Creative Commons Attribution License (CC BY). The use, distribution or reproduction in other forums is permitted, provided the original author(s) or licensor are credited and that the original publication in this journal is cited, in accordance with accepted academic practice. No use, distribution or reproduction is permitted which does not comply with these terms. 